\title{
Mathematical model and parametric uncertainty analysis of a hydraulic generating system
}

\author{
Beibei Xu ${ }^{\mathrm{a}}$, Diyi Chen*a,b ${ }^{\mathrm{a}}$, Edoardo Patelli ${ }^{\mathrm{c}}$, Haijun Shen ${ }^{\mathrm{d}}$, Jae-Hyun Park ${ }^{\mathrm{e}}$ \\ ${ }^{\mathrm{a}}$ Institute of Water Resources and Hydropower Research, Northwest A\&F University, Shaanxi \\ Yangling 712100, P. R. China \\ ${ }^{b}$ Key Laboratory of Agricultural Soil and Water Engineering in Arid and Semiarid Areas, Ministry of \\ Education, Northwest A \& F University, Shaanxi Yangling 712100, P. R. China \\ ${ }^{c}$ Institute for Risk and Uncertainty, Chadwick Building, University of Liverpool, Peach Street, \\ Liverpool L69 7ZF, United Kingdom \\ ${ }^{d}$ The Yellow River Qinghai Hydropower Development Co., Ltd., Qinghai Xining 810000, P. R. China \\ ${ }^{e}$ School of Computer Science and Engineering, Chung-Ang University, 84 Heukseok-Ro, \\ Dongjak-Ku, Seoul 06974, Republic of Korea
}

\section{Corresponding author: Diyi Chen}

Mailing Address: Institute of Water Resources and Hydropower Research, Northwest A\&F University, Shaanxi Yangling 712100, China

Telephones: 086-181-6198-0277

E-mail: diyichen@nwsuaf.edu.cn

\begin{abstract}
Conversion efficiency and unit vibration are two important indexes in evaluating the stability of hydraulic generating systems (HGSs). Most of related studies have been carried out in the deterministic theory framework. As running times of HGS increased, understanding uncertainties and limitations of model parameters are important for accurate modeling and stability evaluation. In this study, first, we establish an integrated model of a HGS by proposing unbalanced hydraulic forces based on the Kutta-Zhoukowski assumption. Second, global sensitivity and parametric interactions for conversion efficiency and unit vibration are investigated based on this model. Finally, the novel unified model is verified with two conventional models. This integrated and accurate mathematical model is a major advance in the diagnosis and prediction of failures in hydropower operation.
\end{abstract}


Keywords: hydraulic generating systems; parametric uncertainty; global sensitivity; conversion efficiency; unit vibration;

\section{Introduction}

In the next 30 years, global hydropower capacity will be doubled roughly from the current 1 billion $\mathrm{kW}$ to 2 billion $\mathrm{kW}[1,2]$. The ongoing challenge with increasing number of hydropower stations is stability evaluation of HGSs. Conversion efficiency and unit vibration are two important indexes in evaluating the stability of a HGS. Historically, stability modeling has been split in two directions (see Fig. 1), focusing on the hydro-turbine governing systems (HTGSs) [3] and the shaft systems of hydro-turbine generator units (SSHTGs) [4].

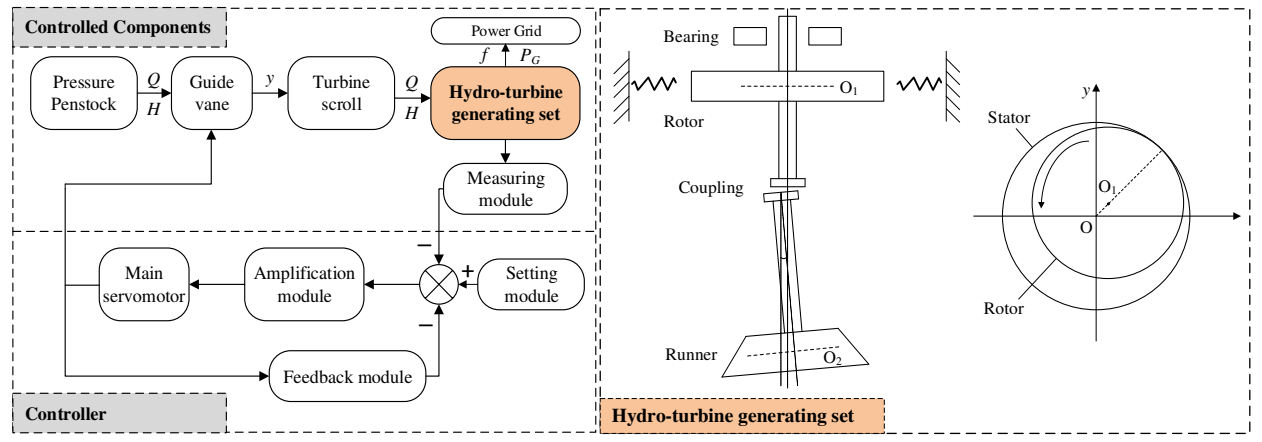

$\begin{array}{ll}\text { (a) A hydro-turbine governing system } & \text { (b) A hydro-turbine generator set }\end{array}$

Fig. 1 The two important research directions of the hydraulic generating system. e.g. (a) the hydro-turbine governing system (HTGS); and (b) the shaft systems of hydro-turbine generator units (SSHTG). The two structure show that HTGS models are designed to provide reliable services to the grid by controlling the turbine speed, but ignore shaft axis vibration; conversely, SSHTG modeling attempts to control vibrations rather than speed. Block of $\square$ means that the two direction models can be unified by some common factors in the SSHTG. Variables $Q, H, y, f$, and $P_{G}$ refer to the turbine flow, the head water, the guide vane opening, the rotational frequency, and the generator magnetic power, respectively.

The HTGS consists of penstocks, hydro-turbines, governors, generators, and surge tanks. The configurations of subsystems are various for each hydropower station. Since most of the differences come from penstocks and generators, we sum up the impacts of these two subsystems on dynamic characteristics of HTGS in Tab. 1 and Tab. 2. The HTGS models that have been recently developed provide new theories to design controller using high dimensional equations. Sarasua et al. proposed two governor tuning criteria for a long penstock pumped-storage plant [5]. Li et al. introduced 
Hamiltonian theory to investigate transient stability of a HGS [6]. Riasi et al made sensitivity analysis of transient flow and numerical analysis of the hydraulic transient response $[7,8]$.

The SSHTG is usually simplified as the generator rotor, generator shaft, turbine runner, and turbine shaft. The SSHTG models are established based on the forces, which usually include oil film forces [4], asymmetric magnetic pull forces [23], and damping forces [24]. The main target of SSHTG models was studied to improve the modeling accuracy. Xu et al. proposed a fractional order model that broadens ranges of amplitude responses by tuning the value of the fractional order [23]. Zeng et al. integrated the SSHTG into the framework of the generalized Hamiltonian system to investigate its vibration characteristics [19].

For the HTGS models, they concern with structures of hydropower stations and ignore dynamic forces acting on the SSHTG. By the way, such SSHTG models involved with the forces and neglect structures of penstocks. They also independently studied the stability for each subsystem. Also, they assumed that parameters were deterministic. In real power stations, some parameters of HTGS and SSHTG are not precisely known or cannot be measured, of which the uncertainties make a difference in efficiency and vibration.

Motivated by the above discussions, first, we propose expressions of unbalanced hydraulic forces on the unit shafting to model hydraulic generating system. We consider both the structures and the forces to make the model. Second, we investigate whole sensitivity and uncertainty of parameters regarding for conversion efficiency and unit vibration. Third, we verify the model with two proposed conventional models.

Tab. 1 Penstock models for HTGS.

\begin{tabular}{ccc}
\hline Penstock simulation & Advantages & Drawbacks \\
\hline Rigid model $[9,10]$ & Simple calculation and sufficient accuracy. & $\begin{array}{c}\text { Modeling inaccuracy when length of } \\
\text { penstock } L>200 \mathrm{~m}\end{array}$ \\
First order elastic & Modeling accuracy relates to any length of the & First oscillation modes between hydraulic \\
\hline
\end{tabular}


model [11-13]

Second order elastic

model [14]

Third order elastic model [15] penstock.

Second oscillation modes of

hydro-mechanic-electric factors are reflected.

Higher oscillation modes of coupling factors are reflected. system and mechanic system are ignored

Complex calculation process

Complex calculation process

Tab. 2 generator models for HTGS.

\begin{tabular}{ccc}
\hline Generator simulation & Advantages & Drawbacks \\
\hline $\begin{array}{c}\text { First-order model [19, } \\
\text { 20] }\end{array}$ & Simple calculation & Modeling inaccuracy, especially in the transient \\
process.
\end{tabular}

This paper is structured as follows. We present an HGS model in Section 2. In Section 3, we analyze the parameters in the model. In Section 4, we investigate the sensitivity and uncertainty analysis of the parameters for conversion efficiency and unit vibration and explain the HGS model in the uncertainty theory framework. Finally, conclusions are given in Section 5.

\section{Model of HGS}

\subsection{Turbine runner modeling}
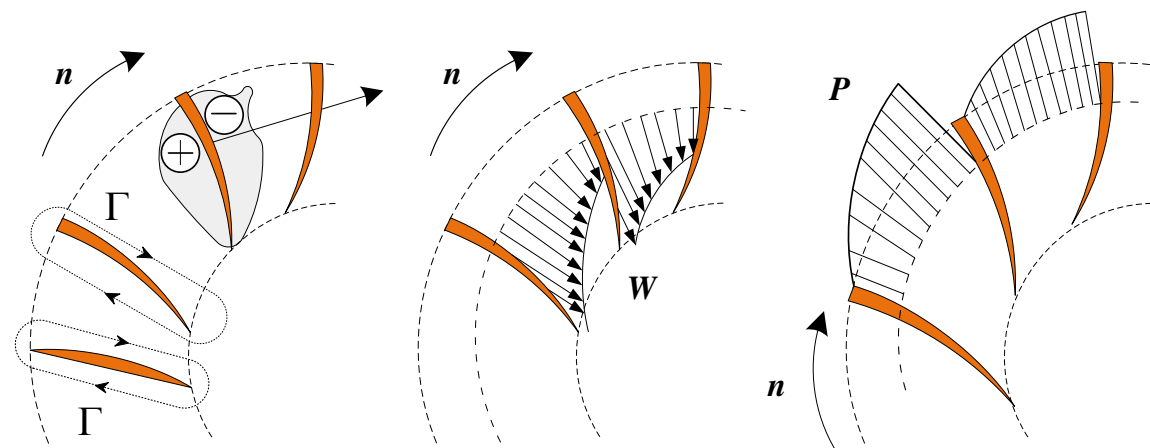

Fig. 2 Hydraulic forces acting on the blade of the turbine runner. Variables $\Gamma, W, n$ and $P$ are the average circulation of the blade, the relative velocity around the blade, the generator speed, and the pressure in passageway between the two blades. Symbols " $\oplus$ " and " $\ominus$ " indicate that the pressure at the side of " $\oplus$ " is larger than that of the side of "Ө”.

The lift force of flowing water acting on a runner blade is [25]

$$
R=\rho W_{m a} \Gamma_{a},
$$


where $W_{m a}$ is the average value of the relative velocity around the blade; $\Gamma_{a}$ is the average circulation. Hydraulic forces acting on the blade of the turbine runner see Fig. 2. Under Kutta-Joukowski condition, the joint force of the blade is [25]

$$
P_{m}=\frac{\gamma C_{y} F W_{m}^{2} \cos \left(\beta_{m}-\lambda\right)}{2 g \cos \lambda},
$$

where $\gamma$ is the liquid weight around the runner blade; $C_{y}$ is the lift coefficient of the runner blade; $C_{x}$ is the resistance coefficient of runner blade, $\lambda=\arctan \frac{C_{X}}{C_{y}} ; F$ is the maximum area of the runner blade; $W_{m}$ is the average relative velocity of the turbine runner, $W_{m}=\sqrt{W_{1} \times W_{2}} ; W_{1}$ is the relative velocity at point 1 (see Fig. $4 \mathrm{a}$ ), $W_{1}=\frac{4 Q}{\pi D_{1}^{2}} ; W_{2}$ is the relative velocity at point 2 (see Fig. 4a); $\beta_{m}$ is the angle between the average relative velocity $\left(W_{m}\right)$ and convected velocity $(U)$ (see Fig. 4c);

When the Reynolds number changes in the interval $\left(10^{4}, 10^{6}\right)$, the resistance coefficient $C_{x}$ and the radio $\lambda$ are expressed as [26]

$$
\left\{\begin{array}{l}
C_{x}=2 \sin \left(\frac{\arcsin C_{y}}{2}\right)^{2} \\
\lambda=\arctan \frac{C_{x}}{C_{y}}=\arctan \frac{2 \sin \left(\frac{\arcsin C_{y}}{2}\right)^{2}}{C_{y}}
\end{array}\right.
$$

The velocity at point 1 or 2 (see Fig. 3a) is reduced to the relative velocity expressed by symbol $W$, the convected velocity represented by $U$, and the absolute velocity of $V . \quad \beta$ is the angle between the relative velocity $W$ and the velocity $U . \alpha$ is the angle between the absolute velocity $V$ and the velocity $U$. Subscript 1 refers to the velocities at the runner inlet, and the subscript 2 refers to the velocities at the runner outlet. 


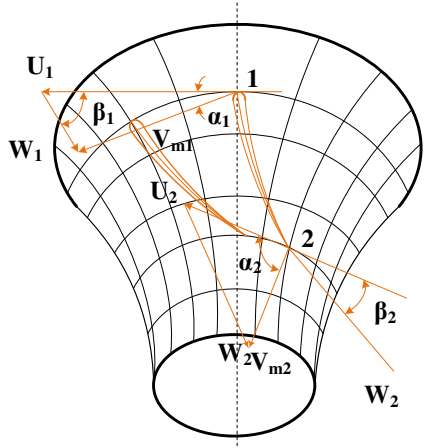

(a) Velocity triangle of the turbine runner. triangle of the blade.

Fig. 3 Francis turbine runner and the velocity triangle of the blade. Variables $U, V$, and $W$ are the convected velocity, absolute velocity, and relative velocity for the blade at the inlet, respectively; $\beta$ is the angle between $W$ and $U ; \alpha$ is the angle between $V$ and $U$; Subscripts 1 and 2 refer to the runner inlet and outlet points. $P_{m 1}$ and $P_{m 13}$ are both the unbalanced hydraulic forces of a pair of runner blades (Number 1 and 13); $\alpha_{1}$ and $\alpha_{13}$ are the position angles of blades 1 and 13 , respectively; $\beta_{\mathrm{m}}$ is the angle between the average relative velocity $\left(W_{m}\right)$ and convected velocity $(U) ; W_{m}$ is the average relative velocity of the turbine runner.

The relative flow velocity at the inlet is [26]

$$
W_{1}=\frac{V_{m 1}}{\sin \beta_{1}}=\frac{Q}{\pi s_{1} b_{0} D_{1} \sin \beta_{1}} .
$$

where $Q$ is the hydro-turbine flow; $s_{1}$ is the excretion coefficient at point $1 ; b_{0}$ is the height of the blade; $\beta_{1}$ is the angle between $W_{1}$ and $U_{1}$ (see Fig. $3 a$ ). $D_{1}$ is the diameter of the hydro-turbine runner at the inlet. From Fig. 3c, the relative flow velocity at the outlet is

$$
\left\{\begin{array}{l}
W_{2}=\frac{V_{m 2}}{\sin \beta_{2}} \\
V_{m 2}=\frac{Q}{F_{2}}=\frac{Q}{s_{2} \pi D_{2}{ }^{2}}
\end{array} .\right.
$$

Let us define the direction of the convected velocity as the $x$-axis (see Fig. 3c). Then, the coordinates of the velocity $W_{1}, W_{2}$, and $W_{\mathrm{m}}$ are $\left(W_{1} \cos \beta_{1}, W_{1} \sin \beta_{1}\right),\left(W_{2} \cos \beta_{2}, W_{2} \sin \beta_{2}\right)$, and $\left(W_{1} \cos \beta_{1}+W_{2} \cos \beta_{2}\right.$, $\left.W_{1} \sin \beta_{1}+W_{2} \sin \beta_{2}\right)$, respectively. Hence, the absolute value of $W_{\mathrm{m}}$ is

$$
\left|W_{m}\right|=\sqrt{W_{1}^{2}+W_{1}^{2}+2 W_{1} W_{2} \cos \left(\beta_{1}-\beta_{2}\right)} .
$$

The angle between the velocity $W_{\mathrm{m}}$ and the convected velocity is

$$
\beta_{m}=\arcsin \frac{W_{1} \sin \beta_{1}+W_{2} \sin \beta_{2}}{\left|W_{m}\right|} .
$$


With Eq. (6) and Eq. (7), Eq. (2) is detailed as

$$
P_{m}=\frac{\gamma C_{y} F \cos \left(\beta_{m}-\lambda\right)}{2 g \cos \lambda}\left(W_{1}^{2}+W_{1}^{2}+2 W_{1} W_{2} \cos \left(\beta_{1}-\beta_{2}\right)\right)
$$

If the initial angle of the blade is $\alpha_{0}$, then the position angle of the blade at time $t$ is

$$
\alpha=\alpha_{0}+\omega t
$$

The component forces of $P_{m}$ in the $X$-direction and $Y$-direction are

$$
\left\{\begin{array}{l}
P_{x}=P_{m} \cos \alpha \\
P_{y}=P_{m} \sin \alpha
\end{array} .\right.
$$

Theoretically, the water flowing in the turbine runner is the axisymmetric spatial flow. In actual situations, there are radial asymmetry forces relative to the center of turbine runner due to the manufacturing deviations of the blades at the outlet edges. For example, assuming a pair of runner blades (numbered 1 and 13) exists the manufacturing deviation.

Let us define the relative velocity at the outlet edge as $W_{21}$, and define the angle between the relative velocity and the circumferential direction of blade 1 as $\beta_{21}$ (see Fig. 3c). Also, let us define the relative velocity for another blade is $W_{22}$, and define the angle between the relative velocity and the circumferential direction of convected velocity for the blade is $\beta_{22}$ (see Fig. 3c). Let us define the angle between the velocity $W_{21}$ and the convected velocity as $\beta_{\mathrm{m} 1}$. In light of Eqs. (1-10), the expression of $\beta_{\mathrm{m} 1}$ is

$$
\beta_{m 1}=\arcsin \frac{W_{1} \sin \beta_{1}+W_{21} \sin \beta_{21}}{\left|W_{m 1}\right|}
$$

Similarly, if we define the angle between the velocity $W_{22}$ and the convected velocity for other blades as $\beta_{\mathrm{m} 2}$, then we can derive as

$$
\beta_{m 2}=\arcsin \frac{W_{1} \sin \beta_{1}+W_{22} \sin \beta_{22}}{\left|W_{m 2}\right|} .
$$

In light of the above analysis, the unbalanced hydraulic forces (see Fig. 3(b)) are 


$$
\left\{\begin{array}{l}
P_{x}=P_{m 1} \cos \alpha_{1}-P_{m 13} \cos \alpha_{13}=\frac{\gamma C_{y} F|\cos \alpha|}{2 g \cos \lambda}\left[A_{1} \cos \left(\beta_{m 1}-\lambda\right)-A_{2} \cos \left(\beta_{m 2}-\lambda\right)\right] \\
P_{y}=P_{m 1} \sin \alpha_{1}-P_{m 13} \sin \alpha_{13}=\frac{\gamma C_{y} F|\sin \alpha|}{2 g \cos \lambda}\left[A_{1} \cos \left(\beta_{m 1}-\lambda\right)-A_{2} \cos \left(\beta_{m 2}-\lambda\right)\right]
\end{array},\right.
$$

where $\left\{\begin{array}{l}A_{1}=\frac{Q^{2}}{\left(s_{1} \pi D_{1}^{2} \sin \beta_{1}\right)^{2}}+\frac{Q^{2}}{\left(s_{2} \pi D_{2}^{2} \sin \beta_{21}\right)^{2}}+\frac{2 Q^{2} \cos \left(\beta_{1}-\beta_{21}\right)}{s_{1} s_{2} \pi^{2} D_{1}^{2} D_{2}^{2} \sin \beta_{1} \sin \beta_{21}} \\ A_{2}=\frac{Q^{2}}{\left(s_{1} \pi D_{1}^{2} \sin \beta_{1}\right)^{2}}+\frac{Q^{2}}{\left(s_{2} \pi D_{2}^{2} \sin \beta_{22}\right)^{2}}+\frac{2 Q^{2} \cos \left(\beta_{1}-\beta_{22}\right)}{s_{1} s_{2} \pi^{2} D_{1}^{2} D_{2}^{2} \sin \beta_{1} \sin \beta_{22}}\end{array}\right.$.

From ref. [25], the torque of the hydraulic turbine is

$$
m_{t}=\rho \frac{Q}{2 \pi Z}\left(\Gamma_{1}-\Gamma_{2}\right)=\frac{\rho Q}{Z}\left[\left(\frac{\cot \alpha}{b_{0}}+\frac{r_{2} \eta_{0}}{F_{2} \varphi} \cot \beta_{21}\right) Q-\omega r_{2}^{2}\right] .
$$

where $Z$ is the blade number. The torque of the hydraulic turbine caused by the unbalanced hydraulic forces is rewritten as

$$
m_{t n}=\frac{1}{Z} \rho Q\left[\left(\frac{\cot \alpha}{b_{0}}+\frac{r_{2} \eta_{0}}{F_{2} \varphi} \cot \beta_{21}\right) \frac{1}{Z} Q-\omega r_{2}^{2}\right]+\frac{1}{Z} \rho Q\left[\left(\frac{\cot \alpha}{b_{0}}+\frac{r_{2} \eta_{0}}{F_{2} \varphi} \cot \beta_{22}\right) \frac{1}{Z} Q-\omega r_{2}^{2}\right] .
$$

Hence, the torque of the hydraulic turbine is

$$
\begin{aligned}
m_{t} & =\frac{Z-2}{Z} \rho Q\left[\left(\frac{\cot \alpha}{b_{0}}+\frac{r_{2} \eta_{0}}{F_{2} \varphi} \cot \beta_{21}\right) \frac{1}{Z} Q-\omega r_{2}^{2}\right]+m_{t n} \\
& =\frac{Z-1}{Z} \rho Q\left[\left(\frac{\cot \alpha}{b_{0}}+\frac{r_{2} \eta_{0}}{F_{2} \varphi} \cot \beta_{21}\right) \frac{1}{Z} Q-\omega r_{2}^{2}\right]+\frac{1}{Z} \rho Q\left[\left(\frac{\cot \alpha}{b_{0}}+\frac{r_{2} \eta_{0}}{F_{2} \varphi} \cot \beta_{22}\right) \frac{1}{Z} Q-\omega r_{2}^{2}\right]^{.}
\end{aligned}
$$

The basic equation of the generator speed is [9]

$$
\left\{\begin{array}{l}
\dot{\omega}=\frac{1}{T_{a b}}\left(m_{t}-m_{e}\right) \\
m_{t 1}=A_{t} h_{t}\left(q_{t}-q_{n l}\right)-D_{t} \omega
\end{array} .\right.
$$

where $m_{e}$ is the electromagnetic moment; $T_{a b}$ is the inertia time constant of the generator; $A_{t}$ is the turbine gain; $h_{t}$ is the water head of hydro-turbine; $q_{t}$ is the hydro-turbine flow; $q_{n l}$ is the hydro-turbine flow at the no-load condition; $D_{t}$ is the damping coefficient of generator; $\omega$ is the generator speed. $m_{t 1}$ is the hydro-turbine torque, which is proposed by IEEE Group in 1992 and then widely used in modeling the hydro-turbine governing system. In this manuscript, the torque $m_{t 1}$ is 
replaced by Eq. (16). Hence, the generator speed is further detailed as

$$
\begin{aligned}
\dot{\omega} & =\frac{1}{T_{a b}}\left(m_{t}-m_{e}-e_{n} \omega\right) \\
& =\frac{1}{T_{a b}}\left[\frac{12}{13} \rho Q\left[\left(\frac{\cot \alpha}{b_{0}}+\frac{r_{2} \eta_{0}}{F_{2} \varphi} \cot \beta_{21}\right) \frac{12}{13} Q-\omega r_{2}^{2}\right]+\frac{1}{13} \rho Q\left[\left(\frac{\cot \alpha}{b_{0}}+\frac{r_{2} \eta_{0}}{F_{2} \varphi} \cot \beta_{22}\right) \frac{1}{13} Q-\omega r_{2}^{2}\right]-m_{e}-e_{n} \omega\right]
\end{aligned}
$$

\subsection{Model of SSHTG}

The SSHTG is divided into four parts, namely the generator rotor, the generator shaft, the turbine runner and the turbine shaft as shown in Fig. 4. Symbols $m_{1}$ and $m_{2}$ are respectively defined as the quality of the generator rotor and the turbine runner. Symbols $O_{1}$ and $O_{2}$ are respectively defined as the centroid of the generator rotor and the turbine runner. Symbol $\alpha$ is defined as the misalignment angle of the generator shaft and the turbine shaft. Symbol $d$ is the misalignment distance of the generator shaft and the turbine shaft. Symbols $k_{1}$ and $k_{2}$ represent the bearing stiffness of the generator rotor and the turbine runner.

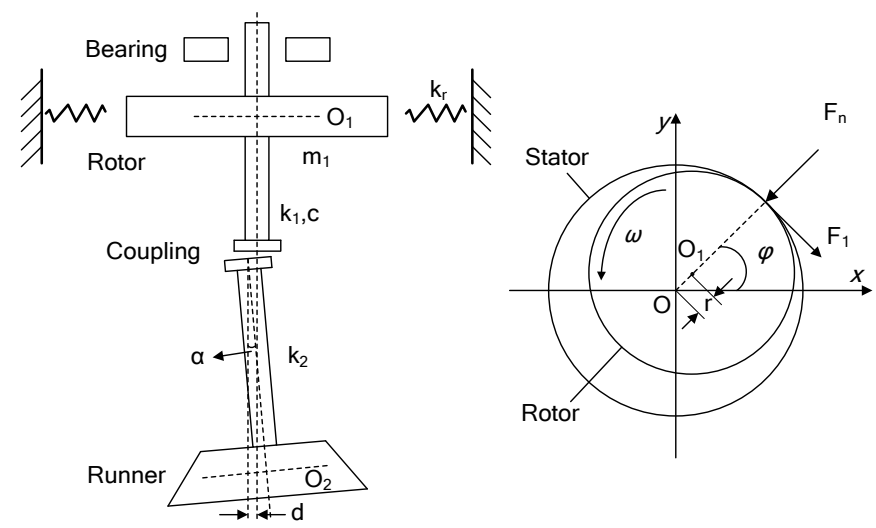

Fig. 4 The shaft system of a hydro-turbine generator unit

Tab. 3 Forces acting on different parts of the shaft system of a hydro-turbine generator unit

\begin{tabular}{ccccccc}
\hline Number & Part & $\begin{array}{c}\text { Rub } \\
\text { impact }\end{array}$ & $\begin{array}{c}\text { Oil-film } \\
\text { force }\end{array}$ & $\begin{array}{c}\text { Damping } \\
\text { force }\end{array}$ & $\begin{array}{c}\text { Asymmetric } \\
\text { magnetic pull }\end{array}$ & $\begin{array}{c}\text { Unbalanced } \\
\text { hydraulic forces }\end{array}$ \\
\hline 1 & Bearing & & $\sqrt{ }$ & & & \\
2 & Rotor & $\sqrt{ }$ & $\sqrt{ }$ & & \\
3 & Rotor shaft & & $\sqrt{ }$ & & \\
4 & Turbine shaft & & $\sqrt{ }$ & & $\sqrt{ }$ \\
5 & Turbine runner & & & $\sqrt{ }$ & & \\
\hline
\end{tabular}

As summarized in Tab. 3, five forces are acting on the parts of the SSHTG. We evaluate these forces as the following: 
1) The rub-impact forces $[23,28]$ : Because of the low speed and great mass of the SSHTG, it is regarded that the system remains rigid during the collision. Hence, the bilinear stiffness model is adopted here.

2) The nonlinear film-oil forces [24, 29]: The pressure acting on the axle diameter is obtained by solving the Reynolds equation.

3) The symmetric magnetic pull [30]: The analytical expression of the asymmetric magnetic pull is obtained by expanding the air gap permeance into Fourier series.

4) The unbalanced hydraulic forces [25]: We use Eq. (13). It is notable that the other SSHTG models treated such forces.

In this manuscript, we adopted the basic system model in ref. [23]. Taking into account the forces acting on the parts (Equation description see Appendix), by combing all equations into a matrix form, we obtain the dynamic equations of the SSHTG as $\left\{\begin{array}{l}\left(m_{1}+m_{2}\right) \dot{x}+c \dot{x}+\left(k_{1}+k_{2}\right) x=\left(m_{1} e_{1}+m_{2} e_{2}\right) \omega^{2} \cos \varphi-k_{2} r \cos \theta+m_{2} r \omega^{2} \cos \theta+F_{x-u m p}+F_{x}-F_{x-r u b}+P_{x} \\ \left(m_{1}+m_{2}\right) \dot{y}+c \dot{y}+\left(k_{1}+k_{2}\right) y=\left(m_{1} e_{1}+m_{2} e_{2}\right) \omega^{2} \sin \varphi-k_{2} r \sin \theta+m_{2} r \omega^{2} \sin \theta+F_{y-u m p}+F_{y}-F_{y-r u b}+P_{y}\end{array}\right.$

where $x$ and $y$ are the derivation of the generator rotor in $x$-axis and $y$-axis; $m_{1}$ and $m_{2}$ are the mass of the generator rotor and the turbine runner, respectively; $k_{1}$ and $k_{2}$ are the bearing stiffness of the generator rotor and the turbine runner, respectively. $c$ is the damping coefficient; $e_{1}$ and $e_{2}$ are the mass eccentricity of the generator rotor and turbine runner; $\omega$ is the generator speed; $\theta$ and $\varphi$ are the position angle of turbine runner and the generator rotor; $r$ is the distance between the center of generator rotor and hydro-turbine runner. $F_{x-u m p}$ and $F_{y-u m p}$ (Equations see Appendix) are the symmetric magnetic pull forces in $\mathrm{x}$-axis and $\mathrm{y}$-axis, respectively; $F_{x}$ and $F_{y}$ (Equations see Appendix) are the film-oil forces; $F_{x-r u b}$ and $F_{y-r u b}$ (Equations see Appendix) are the rub-impact 
forces; $P_{x}$ and $P_{y}$ are the unbalanced hydraulic forces. Detailed calculation process of this model is obtained from ref. [23].

\subsection{Penstock modeling}

The unsteady flow in a pressure penstock is expressed by the following partial differential equation [31]:

$$
\left\{\begin{array}{l}
\frac{\partial H}{\partial x}+\frac{1}{g A} \frac{\partial Q}{\partial t}+\frac{f Q^{2}}{2 g D A^{2}}=0 \\
\frac{\partial Q}{\partial t}+\frac{g A}{a^{2}} \frac{\partial H}{\partial x}=0
\end{array}\right.
$$

From Eq. (20), the relative deviation of water head in the penstock caused by the change of flow is derived as:

$$
h_{q}=Z_{0} q \tanh \left(T_{0} s\right)
$$

where $Z_{0}$ is the normalized value of hydraulic surge impedance of the penstock, or $Z_{0}=\alpha Q_{r} /\left(A_{t} \alpha_{g} H_{r}\right)$. $\alpha$ is water hammer speed. $Q_{\mathrm{r}}$ is the rated turbine flow. $H_{\mathrm{r}}$ is the rated turbine head. $A_{\mathrm{t}}$ is the sectional area of the penstock. $\alpha_{g}$ is the acceleration of gravity. $q$ is the relative flow in the penstock. $T_{0}$ is the elastic time constant of the penstock, $T_{0}=L / \alpha . L$ is the length of the penstock.

According to Laplace transform theorem, the hydraulic turbine flow is written as:

$$
\left\{\begin{array}{l}
\dot{x}_{1}=x_{2} \\
\dot{x}_{2}=x_{3} \\
\dot{x}_{3}=-\frac{\pi^{2}}{T_{01}^{2}} x_{2}+\frac{1}{Z_{01} T_{01}^{3}}\left(h_{0}-f q^{2}-h_{t}\right) \\
\dot{q}=-3 \pi^{2} x_{2}+\frac{4}{Z_{01} T_{01}}\left(h_{0}-f q^{2}-h_{t}\right)
\end{array}\right.
$$

The conversion efficiency of the hydro-turbine is

$$
\eta_{0}=\frac{n_{s}^{2} H^{1.5}}{9.81\left(\frac{30 \omega}{\pi}\right)^{2} Q}=\frac{n_{s}^{2} H^{1.5}}{895.472 \omega^{2} Q} .
$$

The first-order of Eq. (23) is rewritten as:

$$
\dot{\eta}_{0}=-\frac{n_{s}^{2} H^{1.5}}{895.472}\left(2 \frac{\dot{\omega}}{\omega^{3} Q}+\frac{\dot{Q}}{\omega^{2} Q^{2}}\right)=-\frac{n_{s}^{2} H^{1.5}}{895.472}\left(\frac{2 \omega_{m B} \dot{\omega}}{\omega^{3} Q}+\frac{\dot{q} Q_{r}}{\omega^{2} Q^{2}}\right)
$$


where $n_{\mathrm{s}}$ is the specific speed of the hydraulic turbine. $\omega$ is the angular velocity or $\omega=\omega_{m B} x$. By combing all equations into a matrix form, we obtain the dynamic equations of the HGS as

$$
\left\{\begin{array}{l}
\dot{x}_{1}=x_{2} \\
\dot{x}_{2}=x_{3} \\
\dot{x}_{3}=-\frac{\pi^{2}}{T_{01}^{2}} x_{2}+\frac{1}{Z_{01} T_{01}^{3}}\left(h_{0}-f q^{2}-h_{t}\right) \\
\dot{q}=-3 \pi^{2} x_{2}+\frac{4}{Z_{01} T_{01}}\left(h_{0}-f q^{2}-h_{t}\right) \\
\dot{\omega}=\frac{1}{T_{a b}}\left[\frac{12}{13} \rho Q\left[\left(\frac{\cot \alpha}{b_{0}}+\frac{r_{2} \eta_{0}}{F_{2} \varphi} \cot \beta_{21}\right) \frac{12}{13} Q-\omega r_{2}^{2}\right]+\frac{1}{13} \rho Q\left[\left(\frac{\cot \alpha}{b_{0}}+\frac{r_{2} \eta_{0}}{F_{2} \varphi} \cot \beta_{22}\right) \frac{1}{13} Q-\omega r_{2}^{2}\right]-m_{e}-e_{n} \omega\right] \\
\left(m_{1}+m_{2}\right) \dot{x}+c \dot{x}+\left(k_{1}+k_{2}\right) x=\left(m_{1} e_{1}+m_{2} e_{2}\right) \omega^{2} \cos \varphi-k_{2} r \cos \theta+m_{2} r \omega^{2} \cos \theta+F_{x-u m p}+F_{x}-F_{x-r u b}+P_{x} \\
\left(m_{1}+m_{2}\right) \dot{y}+c \dot{y}+\left(k_{1}+k_{2}\right) y=\left(m_{1} e_{1}+m_{2} e_{2}\right) \omega^{2} \sin \varphi-k_{2} r \sin \theta+m_{2} r \omega^{2} \sin \theta+F_{y-u m p}+F_{y}-F_{y-r u b}+P_{y} \\
\dot{\eta}_{0}=-\frac{n_{s}^{2} H^{1.5}}{895.472}\left(2 \frac{\dot{\omega}}{\omega^{3} Q}+\frac{\dot{Q}}{\omega^{2} Q^{2}}\right)=-\frac{n_{s}^{2} H^{1.5}}{895.472}\left(\frac{2 \omega_{m B} \dot{\omega}}{\omega^{3} Q}+\frac{\dot{q} Q_{r}}{\omega^{2} Q^{2}}\right)
\end{array}\right.
$$

\subsection{Uncertainty analysis method}

Uncertainty analysis is an effective method to quantize the parametric uncertainty on the system outputs. Indices $S_{i}$ and $S_{T i}$ are the quantitative indicators from the Extended Fourier Amplitude Sensitivity Text (EFAST) [32, 33]. The corresponding two symbols indicate the single contribution of parameters to the output uncertainty and the interaction effect of multi-parameters on the output uncertainty. Specific calculation process of the two symbols is briefly presented as follows.

Firstly, a suitable search function $G_{i}$ is defined to transform the system model $Y=f\left(x_{1}, x_{2}, \ldots, x_{n}\right)$ to the type of $y=f(s)$ :

$$
\left\{\begin{array}{l}
x_{i}(s)=G_{i}\left[\sin \left(\omega_{i} s\right)\right] \\
\pi\left(1-x_{i}^{2}\right)^{0.5} P_{i} G_{i} \frac{d G_{i}\left(x_{i}\right)}{d x_{i}}=1
\end{array}\right.
$$

where $i$ is the parameter number, $i \in(1, n) ;\{\omega\}$ is defined as the frequency of the integer; $P_{i}$ is the probability density function of the uncertain parameter $x_{i}$. The system model $y=f(s)$ is expressed using Fourier transform method as:

$$
y=f(s)=\sum_{j=-\infty}^{j=+\infty} A_{j} \cos (j s)+B_{j} \sin (j s)
$$


where $\quad A_{j}=\frac{1}{2 \pi} \int_{-\pi}^{\pi} f(s) \cos (j s) d s, \quad B_{j}=\frac{1}{2 \pi} \int_{-\pi}^{\pi} f(s) \sin (j s) d s, \quad j \in\left\{-\frac{N_{s}-1}{2}, \cdots, 0, \cdots,+\frac{N_{s}-1}{2}\right\} . \quad N_{s}$ is the sampling number. Fourier series spectrum curve based on Eq. (2) is

$$
\Lambda_{j}=A_{j}^{2}+B_{j}^{2} .
$$

The variance of uncertainty output caused by parameter $x_{i}$ is

$$
V_{i}=2 \sum_{i=1}^{+\infty} \Lambda_{i} \omega_{i}
$$

The total variance of uncertainty output is

$$
V=\sum_{i} V_{i}+\sum_{i \neq j} V_{i j}+\sum_{i \neq j \neq k} V_{i j k}+\ldots+\sum_{i} V_{12 \cdots n}
$$

where $V_{i j}$ is the variance of parameter $x_{i}$ affected by $x_{j} ; V_{i j m}$ is the variance of parameter $x_{i}$ affected by the coupling of $x_{j}$ and $x_{m} . V_{12 \ldots \mathrm{n}}$ is variance of parameter $x_{i}$ affected by the coupling of $x_{1}, x_{2}$, $x_{3}, \ldots$, and $x_{n}$.

In light of the above analysis, the main effect $S_{i}$ is

$$
S_{i}=\frac{V_{i}}{V}
$$

The total effect $S_{T i}$ is

$$
S_{T i}=\frac{V-V_{-i}}{V}
$$

where $V_{-i}$ does not include the sum of variance regarding $x_{i}$.

\section{Parametric Uncertainty}

The model of the turbine runner is a link between the penstock model and SSHTG model. Since uncertainty in runner model parameters is not taken into account, it is expected that there would exist some inaccuracy when the runner blade and the flowing water interrelate in operation. Based on the proposed model of Eq. (25), we choose six critical parameters from the turbine runner model: the relative height of the guide vane $\left(x x=b_{0} / D_{1}\right)$, the diameter ratio $\left(p p=D_{2} / D_{1}\right)$, the angle $\left(b_{2}=\beta_{21}\right)$, the excretion coefficient $\left(s_{1}\right)$, the manufacturing angle error of the symmetrical blades $\left(b=\beta_{22}-\beta_{21}\right)$, and the lift coefficient $\left(C_{y}\right)$. Also, the gross water head $\left(h_{0}\right)$ and the excitation current $\left(i_{j}\right)$ are selected 
to perform the following studies.

Uncertainty also exists in the models of the penstock and SSHTG. For example, the gross water head $\left(h_{0}\right)$ in the penstock model is essentially changing because of the uncertain difference of the incoming flow and out-coming flow corresponding to the reservoir; the excitation current $\left(i_{j}\right)$ in the SSHTG changes with the fluctuation of the electricity load in a narrow range. Hence, the gross water head $\left(h_{0}\right)$ and the excitation current $\left(i_{j}\right)$ are also selected to perform the following studies.

Considering parameter $x x$, from Ref. [38], its value changes in the interval [0.12, 0.315]. Here, the reference value of parameter $x x$ is attempted to be multiplied by a random factor with a probability law centered on 0.25, which is shown in Fig. 6(a). About parameter $p p$, the different type corresponds to a different diameter ratio. In this study, we mainly investigate the Francis turbine runner operating at middle or high water head. Hence, its value is always less than 1 . Its distribution is assumed similar with parameter $x x$, as shown in Fig. $6(b)$. For parameter $i_{j}$, its impact in different intervals has been investigated by many researchers $[24,29]$. Here, the reference value is attempted to be multiplied by a random factor with a probability law centered on 750 (unit A), which is shown in Fig. 6(c). This interval is widely acceptable by most hydropower stations. From Ref. [34] and the interval of parameter $x x$, the reference value of parameter $\beta_{21}$ is attempted to be multiplied by a random factor with a probability law centered on 0.65 , and its distribution law is shown in Fig. $6(d)$. Similarly, the distributions of parameters $s_{1}, b, C_{y}$ and $h_{0}$ are respectively shown in Figs. 6(e)-6(i). 


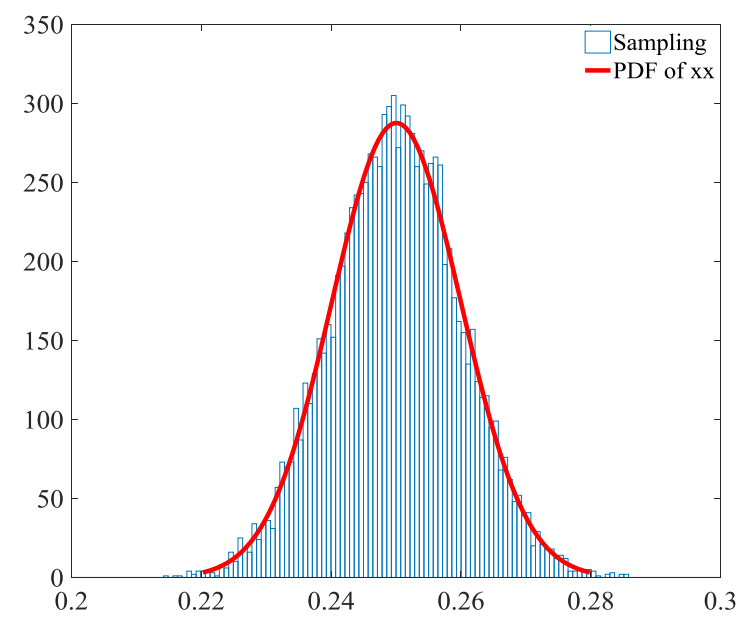

(a) the relative height of the guide vane $x x$.

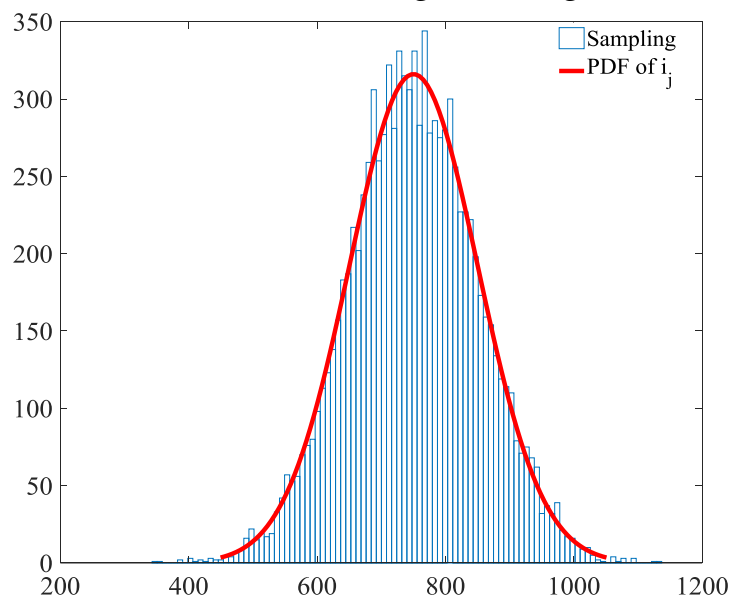

(c) the excitation current $\left(i_{j}\right)$.

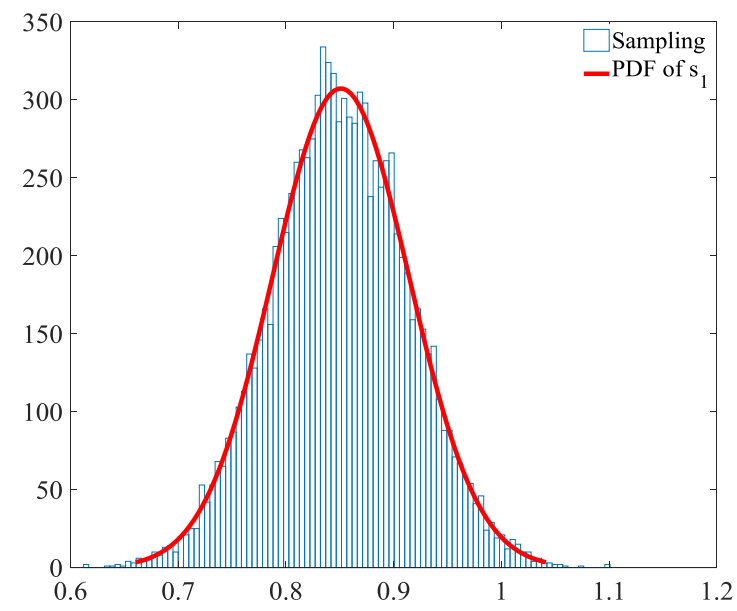

(e) the excretion coefficient $\left(s_{1}\right)$.

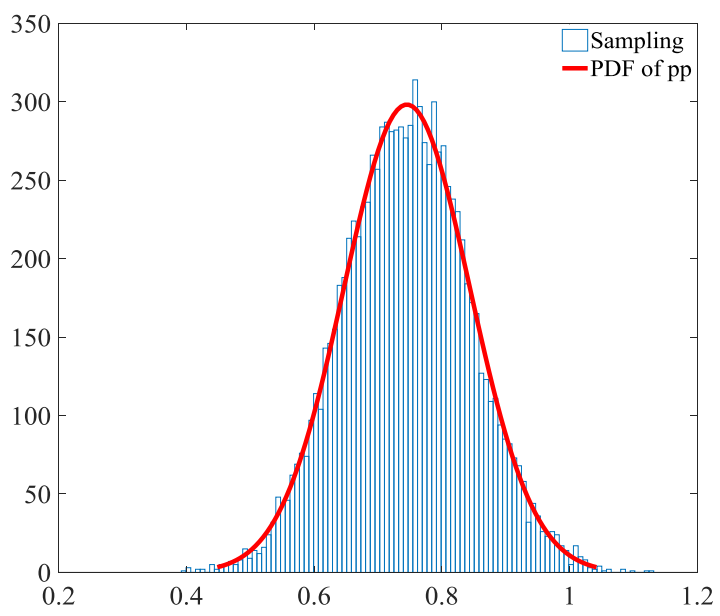

(b) the diameter ratio $p p$.

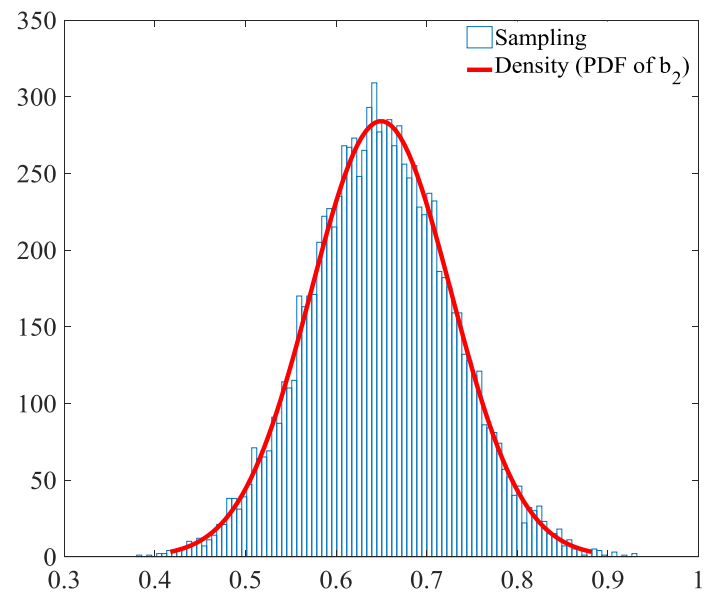

(d) the angle $\left(b_{2}=\beta_{21}\right)$.

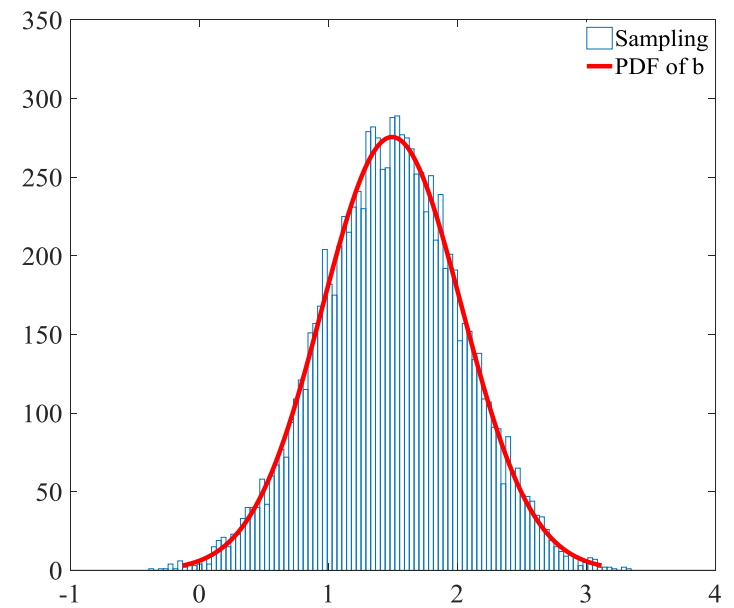

$(f)$ the manufacturing angle error $\left(b=\beta_{22}-\beta_{21}\right)$. 


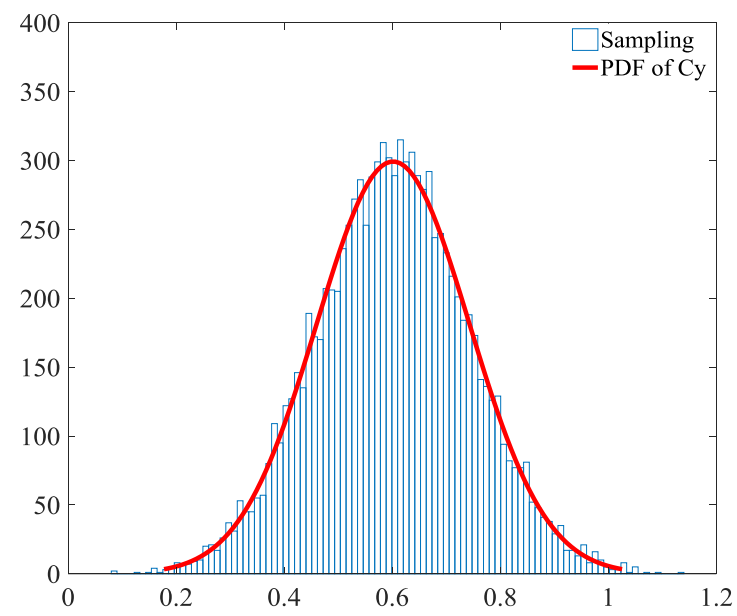

(h) the lift coefficient $\left(C_{y}\right)$.

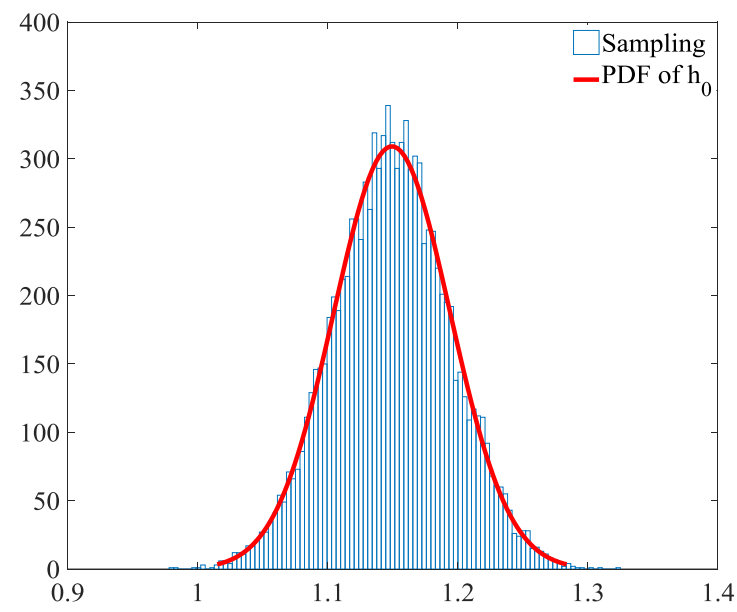

(i) the gross water head $\left(h_{0}\right)$.

Fig. 6 Probability density functions and samplings of the eight uncertain parameters.

\section{Simulation results}

\subsection{Uncertainty outputs}

Combining the models of the turbine runner, the SSHTG, and the penstock, the mathematical model of HGS is established considering parametric uncertainty. As we all know, there is a close correspondence between the conversion efficiency and the unit vibration. Hence, it is very important to understand their relationship by the probability distributions under the impact of the uncertain parameters. Here, calculate ten thousand times to the model to obtain the probability density function of the conversion efficiency and the cumulative density function of axis offsets, which are shown in Fig. 7.

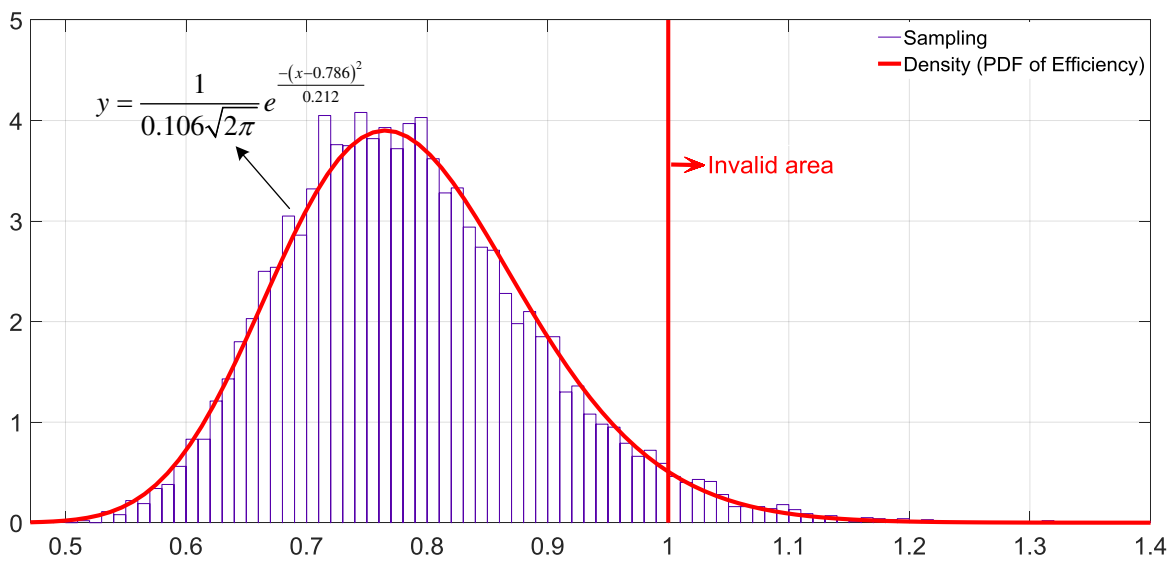

(a) Probability density function of conversion efficiency. 


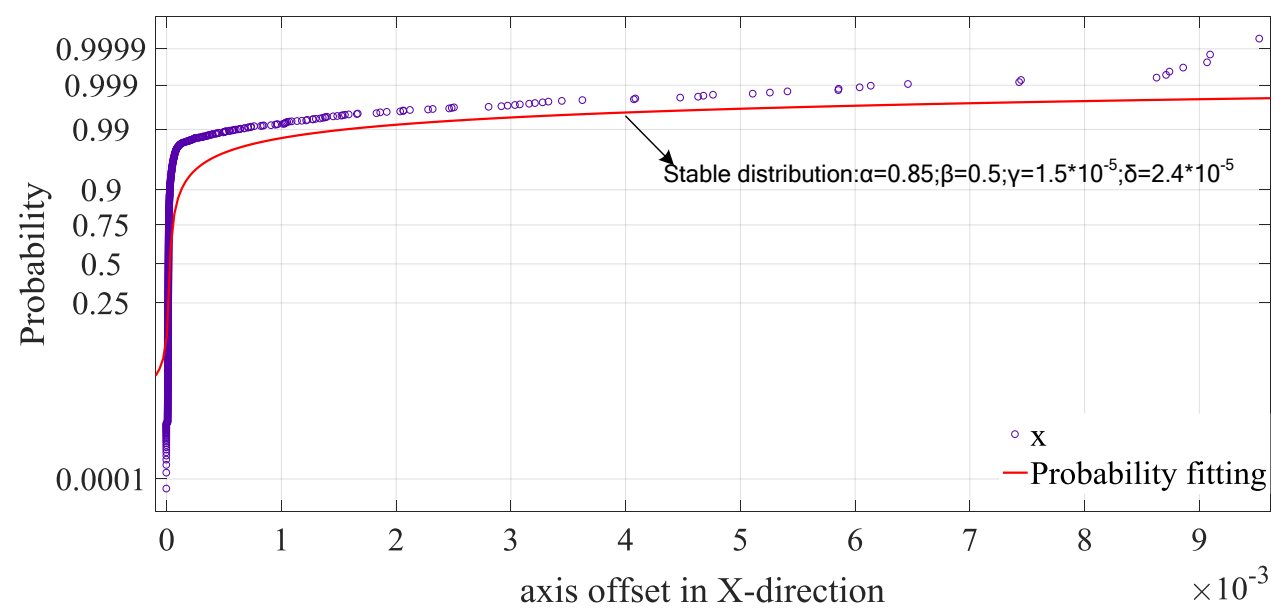

(b) The cumulative density function of axis offset in X-direction.

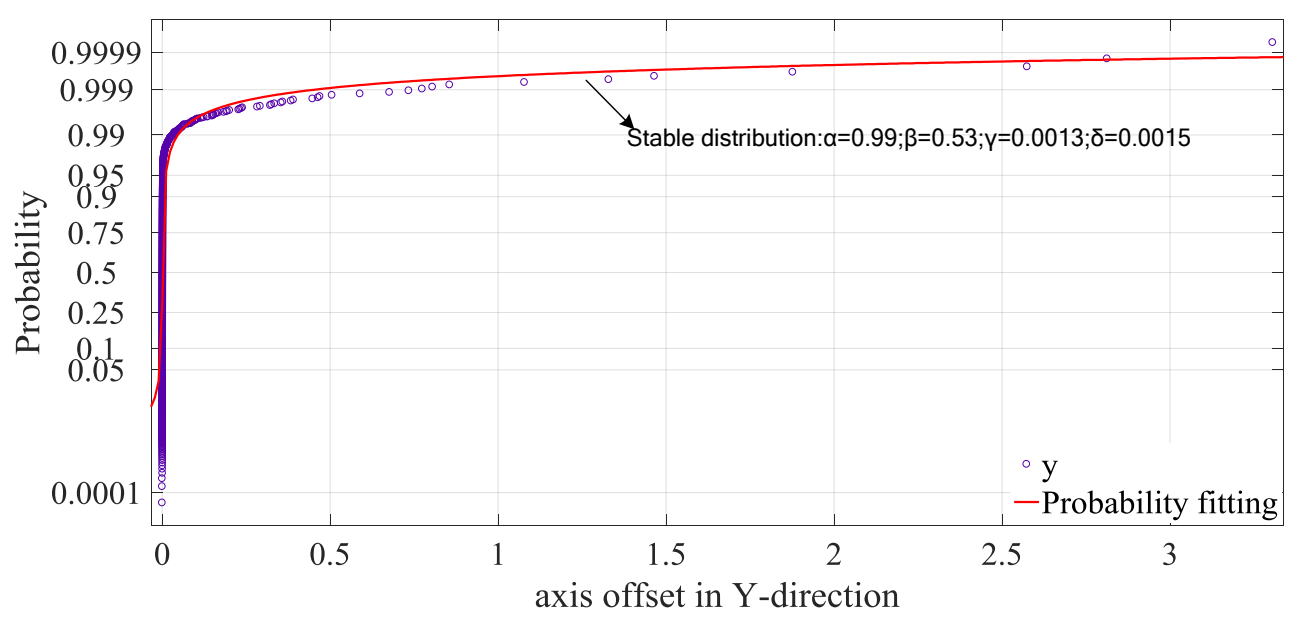

(c) The cumulative density function (CDF) of axis offset in Y-direction.

Fig. 7 Uncertainty outputs of conversion efficiency and unit vibration.

From Fig. 7(a), the uncertainty distribution of the conversion efficiency approximately matches the normal distribution. The average value is 0.786 , and the standard deviation is 0.106 . The highest frequency interval is $[0.7,0.82]$. In the viewpoint of engineering, the conversion efficiency of the generating system operating in the interval $[0.7,0.82]$ has the maximum probability, and stability with standard deviation 0.106 is sufficiently reliable.

From Figs. $7(b, c)$, the uncertainty outputs of the axis offset in $x$-axis and $y$-axis approximately match stable distribution. Specifically, the derivation of $x$ in the interval $(20 \mu \mathrm{m}, 1000 \mu \mathrm{m})$ shows a high probability, and the derivation of $y$ in the interval $(90 \mu \mathrm{m}, 4000 \mu \mathrm{m})$ is likely to happen. From GB/T 8564-2003 of Technical code for installation of hydraulic turbines in China, the limited value 
of the axis offset in $x$-axis and $y$-axis should not exceed $300 \mu \mathrm{m}$. Obviously, the outputs of $x$ and $y$ to the eight uncertain parameters in some intervals are basically meet the standard requirements of hydropower stations.

In light of the above analysis, the definitions of intervals of the eight parameters are reasonable. In the next section, we present how the uncertain parameter impacts on unit vibration and conversion efficiency. In addition, the other parameters in Eq. (25) can be obtained from Tab. 3.

Tab. 3 Specification of the hydropower station for simulation.

\begin{tabular}{|c|c|c|c|c|}
\hline Component & Parameter & Symbol & Value & Unit \\
\hline Penstock & \multicolumn{4}{|c|}{ Material: Steel } \\
\hline \multirow{6}{*}{ Hydro-turbine } & Length & $L$ & 216 & $\mathrm{~m}$ \\
\hline & Diameter & $D_{L}$ & 5 & $\mathrm{~m}$ \\
\hline & \multicolumn{4}{|c|}{ Type: HLD294-LJ-178 } \\
\hline & Maximum head & $H_{\max }$ & 113.5 & $\mathrm{~m}$ \\
\hline & Rated head & $H_{\text {rated }}$ & 103 & $\mathrm{~m}$ \\
\hline & Rated power & $P_{\text {rated }}$ & 29000 & $\mathrm{Kw}$ \\
\hline \multirow{24}{*}{ Generator } & Rated speed & $n_{\text {rated }}$ & 428.6 & $\mathrm{r} / \mathrm{min}$ \\
\hline & Rated flow & $Q_{\text {rated }}$ & 32.86 & $\mathrm{~m}^{3} / \mathrm{s}$ \\
\hline & Zero load flow & $Q_{n l}$ & 4.5 & $\mathrm{~m}^{3} / \mathrm{s}$ \\
\hline & Guide vane opening & $Y_{\max }$ & 205 & $\mathrm{~mm}$ \\
\hline & Zero load guide vane opening & $Y_{n l}$ & $21 \%$ & -- \\
\hline & the mass of the hydro-turbine runner & $m_{2}$ & $1.1 \times 10^{4}$ & $\mathrm{~kg}$ \\
\hline & the damping coefficient & $c$ & $6.5 \times 10^{4}$ & $\mathrm{~N} \cdot \mathrm{s} / \mathrm{m}$ \\
\hline & the bearing stiffness of the runner & $k_{2}$ & $6.5 \times 10^{-7}$ & $\mathrm{~N} / \mathrm{m}$ \\
\hline & the eccentric mass of the runner & $e_{2}$ & 0.0005 & $\mathrm{~m}$ \\
\hline & the initial phase & $\theta_{0}$ & 0.8 & $\mathrm{rad} / \mathrm{s}$ \\
\hline & moment of inertia for the runner & $J_{2}$ & $3.5 \times 10^{6}$ & $\mathrm{~kg} \cdot \mathrm{m}^{2}$ \\
\hline & command signal & $s$ & $10^{-5}$ & -- \\
\hline & \multicolumn{4}{|c|}{ Type: FS29-14/4000 } \\
\hline & Active power & $P_{\text {e-rated }}$ & 29 & MW \\
\hline & Direct axis synchronous reactance & $X_{d}$ & 0.9736 & $\Omega$ \\
\hline & Direct axis transient reactance & $X_{d}$, & 0.2836 & $\Omega$ \\
\hline & Quadrature synchronous axis reactance & $X_{q}$ & 0.6169 & $\Omega$ \\
\hline & Quadrature transient axis reactance & $X_{q}$ & 0.6169 & $\Omega$ \\
\hline & Rated terminal voltage & $U_{S-\text { rated }}$ & 6.3 & $\mathrm{kV}$ \\
\hline & Damping factor & $D_{t}$ & 5 & -- \\
\hline & Transient time constant of axis & $T_{d 0}$ & 5.4 & $\mathrm{~s}$ \\
\hline & Mass of the rotor for the generator & $m_{1}$ & $1.5 \times 10^{4}$ & $\mathrm{~kg}$ \\
\hline & the bearing stiffness of the rotor & $k_{1}$ & $8.5 \times 10^{-7}$ & $\mathrm{~N} \cdot \mathrm{s} / \mathrm{m}$ \\
\hline & the eccentric mass of the rotor & $e_{1}$ & 0.0005 & $\mathrm{~m}$ \\
\hline
\end{tabular}




\subsection{Global sensitivity analysis}

The uncertain outputs presented above make the conclusions sensitive to uncertainties regarding the conversion efficiency and unit vibration. Also, the generator speed is a key parameter that directly affects the connected stability of the generator linking to the electric power system. Hence, in the following, the global sensitivities of the eight uncertain parameters to the conversion efficiency, unit vibration and generator speed are analyzed.

Currently, there is so far no unified standard for sensitivity index. Here, a standard for sensitivity analysis proposed by EDJONGFE is adopted. From the standard requirement, the parameter is sensitive to the outputs when $S_{i}>0.05, S_{T i}>0.1$. Using Monte Carlo method [35, 36] and EFAST, the first order and total order sensitivity analysis results of HGS with eight uncertain random parameters are presented in Fig. 8.

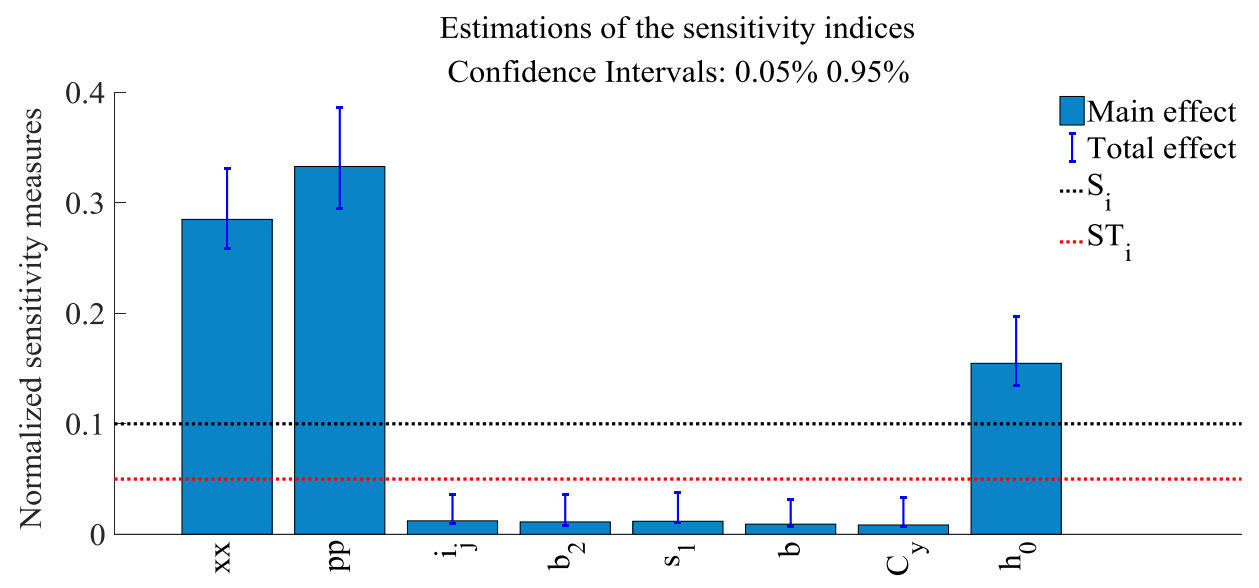

(a) Sensitivity analysis results of the conversion efficiency. 


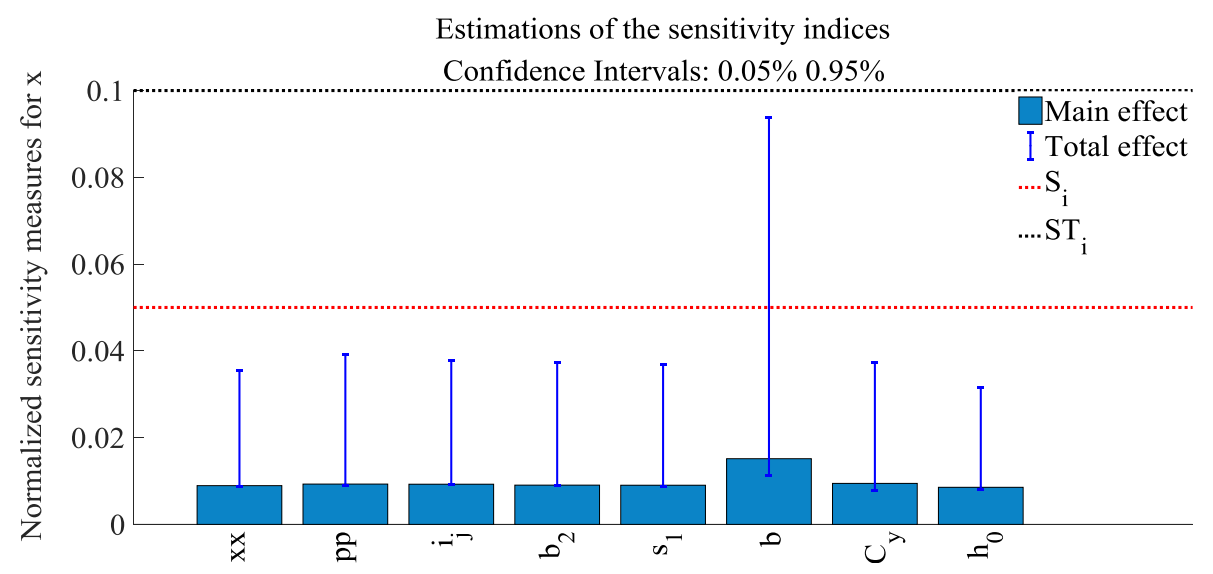

(b) Sensitivity analysis results of axis offset in the x-axis.

Estimations of the sensitivity indices

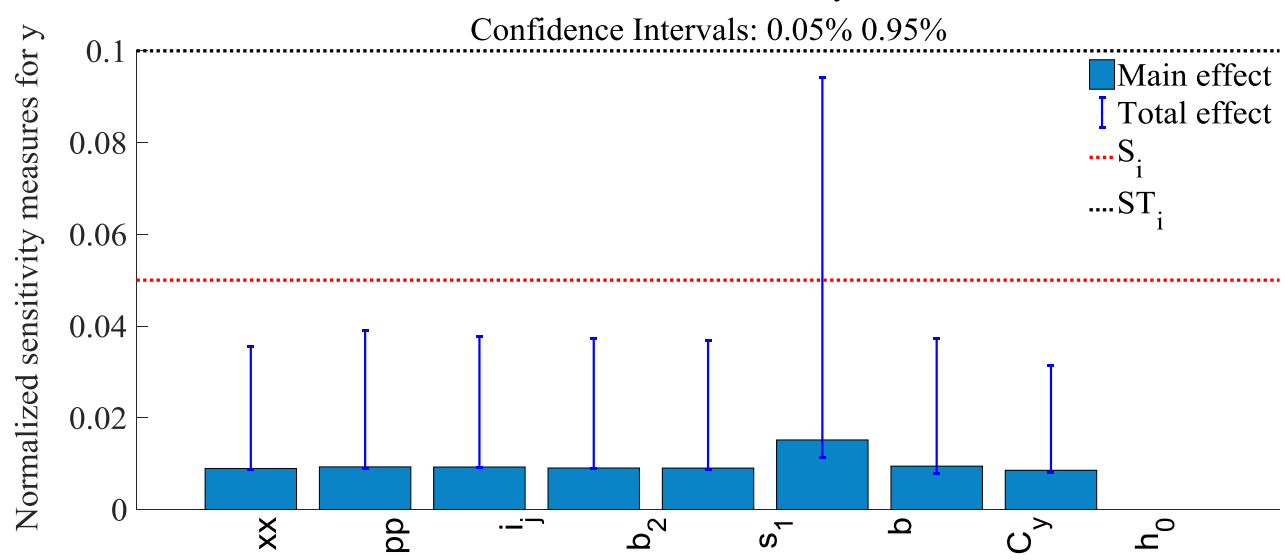

(c) Sensitivity analysis results of axis offset in the $y$-axis.

Estimations of the sensitivity indices

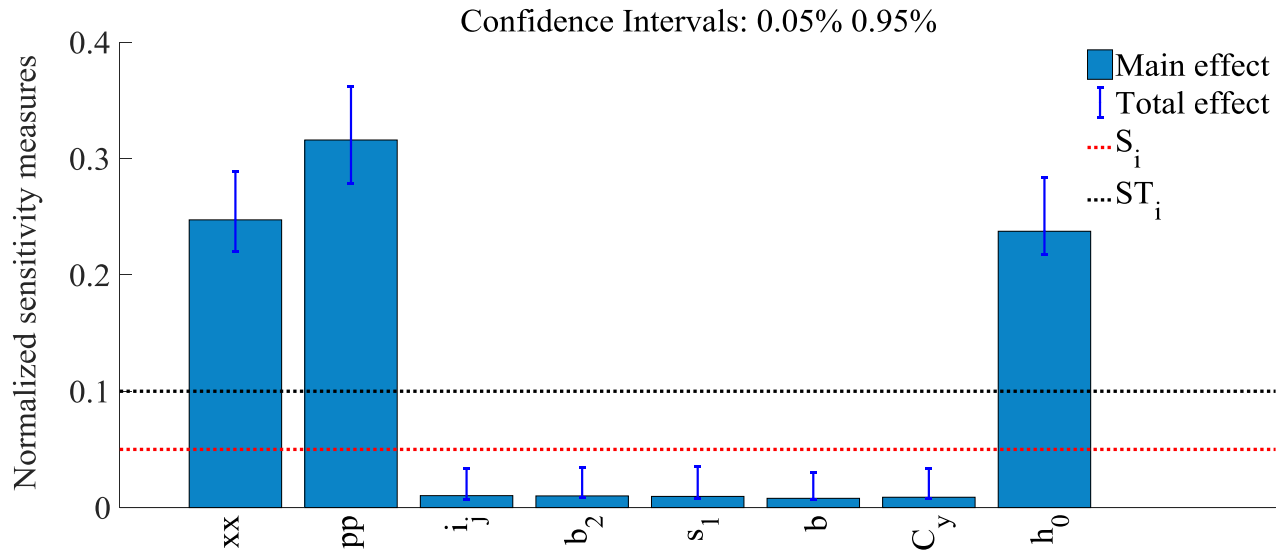

(d) Sensitivity analysis results of the generator speed.

Fig. 8 First order and total order sensitivity analysis results of the hydraulic generating system with eight uncertain random parameters.

From Fig. 8(a), for the conversion efficiency, there are three parameters of which the first order sensitivity and the total order sensitivity exceed the standard requirement, namely the relative height of the guide vane $(x x)$, the diameter ratio $(p p)$, and the gross water head $\left(h_{0}\right)$. Specifically, values of 
$S_{i}$ and $S_{T i}$ to parameters $x x, p p$ and $h_{0}$ are respectively $(0.285,0.0728),(0.333,0.091)$ and $(0.155$, 0.063), which are obviously greater than that of other parameters. In other words, the impact of parameters $x x, p p$ and $h_{0}$ on the conversion efficiency is enormous and could be used to improve the modeling accuracy of a HGS.

Regarding the unit vibration, the values of the first order sensitivity and the total order sensitivity are both less than the standard requirement (see Figs. $8(c, d)$ ). Obviously, using the standard proposed by EDJONGFE is not appropriate. To obtain the impact degree of eight uncertain parameters on unit vibration, the sensitivity values of each parameter and their ranges are present in Tab. 2.

Tab. 2 Sensitivity values and ranges of uncertain parameters concerning unit vibration.

\begin{tabular}{ccccc}
\hline Parameter & $S_{i}$ & Range & $S_{T i}$ & Range \\
\hline$x x$ & 0.008935 & 2 & 0.0268821 & 2 \\
$p p$ & 0.009294 & 6 & 0.0300927 & 7 \\
$i_{j}$ & 0.009261 & 5 & 0.028664 & 5 \\
$b_{2}$ & 0.009050 & 4 & 0.02823019 & 3 \\
$s_{1}$ & 0.009028 & 3 & 0.0283079 & 4 \\
$b$ & 0.015140 & 8 & 0.082501 & 8 \\
$C_{y}$ & 0.009449 & 7 & 0.029459 & 6 \\
H0 & 0.008550 & 1 & 0.0233837 & 1 \\
\hline
\end{tabular}

For the generator speed, the parameters of which the first-order sensitivity index is more than 0.5 include $x x, p p$, and $h_{0}$ that are the same as the sensitive parameters of conversion efficiency.

Summarized the above analysis, first, the conversion efficiency and generator speed have the same sensitive parameters, which are $x x, p p$, and $h_{0}$. Their ranges to impact degree is $p p>x x>h_{0}$. Second, from the sensitivity analysis of unit vibration, we can conclude the vibration is a comprehensive problem. The ranges to impact degree is $h_{0}<x x<s_{1}<b_{2}<i_{j}<p p<C_{y}<b$. The ranges to interaction impact degree is $h_{0}<x x<b_{2}<s_{1}<i_{j}<C_{y}<p p<b$.

\subsection{Interaction contributions}

The contribution of the first order and interactions of eight parameters to conversion efficiency and unit vibration is shown in Fig. 9. The contribution of the first order and interactions of the sum of 
eight parameters to conversion efficiency and unit vibration is shown in Fig. 10. By comparing the sensitive parameters of conversion efficiency and unit vibration in Fig. 9, the deciding factors of unit vibration are more than that of conversion efficiency. On the other hand, from the calculated results of total sensitivity analysis, the interactions of the deciding factors for unit vibration are much greater. Obviously, the contribution rate of these uncertain parameters to conversion efficiency and unit vibration mainly comes from the direction contribution rate of each parameter, and the contribution rate of parameters to interactions is much less. However, the distribution rate of interaction to unit vibration is much higher than that of conversion efficiency, which proportion are respectively 70\%, 30\%, 22\% and 78\%, as shown in Fig. 10.

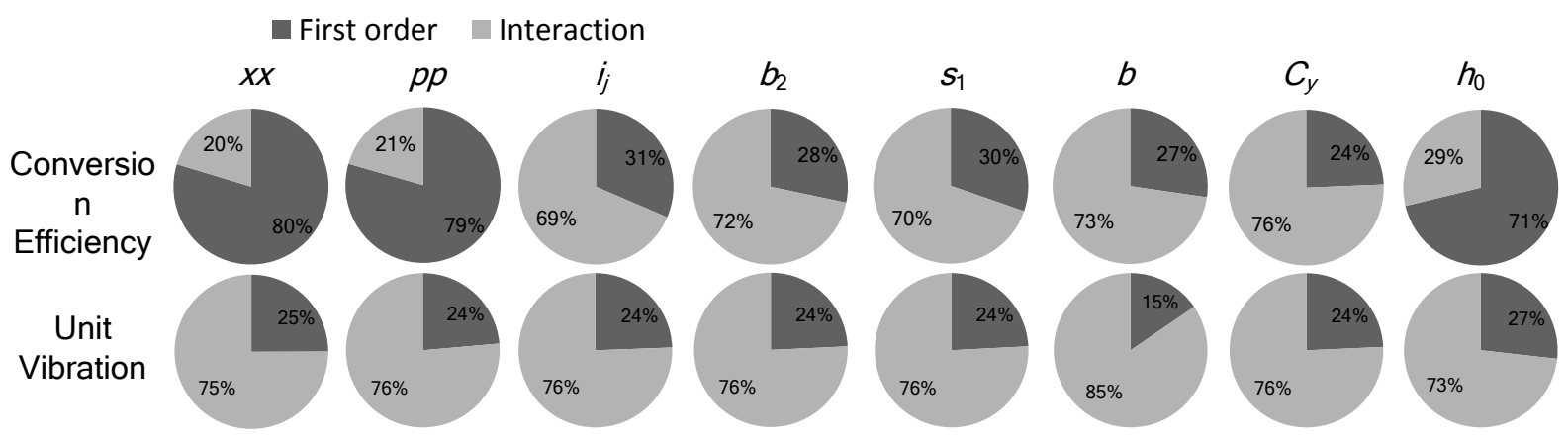

Fig. 9 Contributions of the first order and interactions of eight parameters to conversion efficiency and unit vibration.
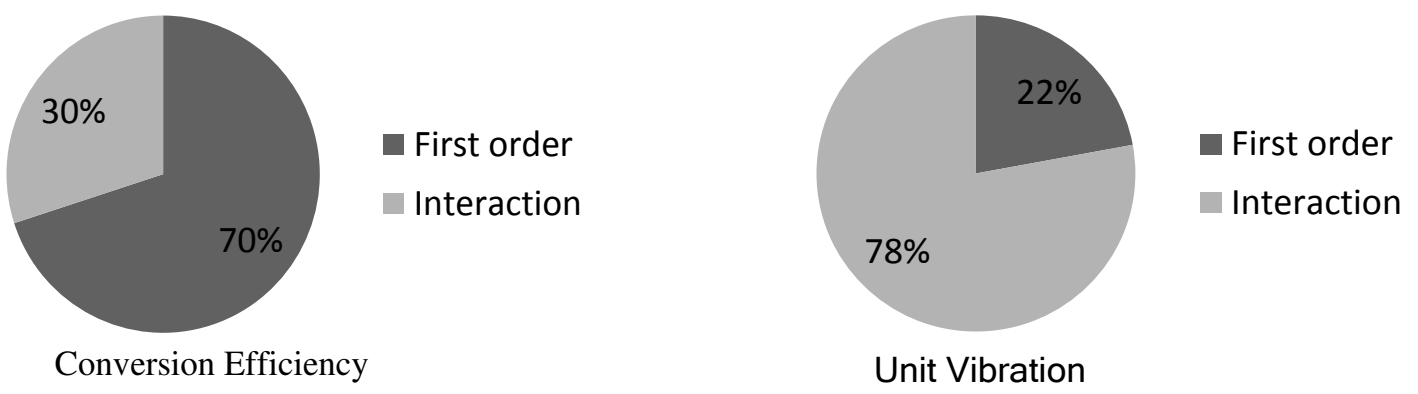

Fig. 10 Contribution of the first order and interactions of the sum of the eight parameters to conversion efficiency and unit vibration.

\subsection{Model verification and New Challenges}

The ability of the HGS containing uncertain random parameters to simulate the HTGS's responses and SSHTG's vibration is performed. Simulations are presented using two conversational models: 
the HTGS' model published in ref. 9, and the SSHTG's model presented in ref. 37. Comparisons of HTGS's responses and modal results performed from different models are presented in Figs. 11, 12 and Tab. 4, respectively. Regarding the SSHTG's responses, the software of Pro/E is used to establish the 3D shafting model, and the element solid95 is adopted for its mesh generation. The grid includes 59022 units and 28879 nodes.

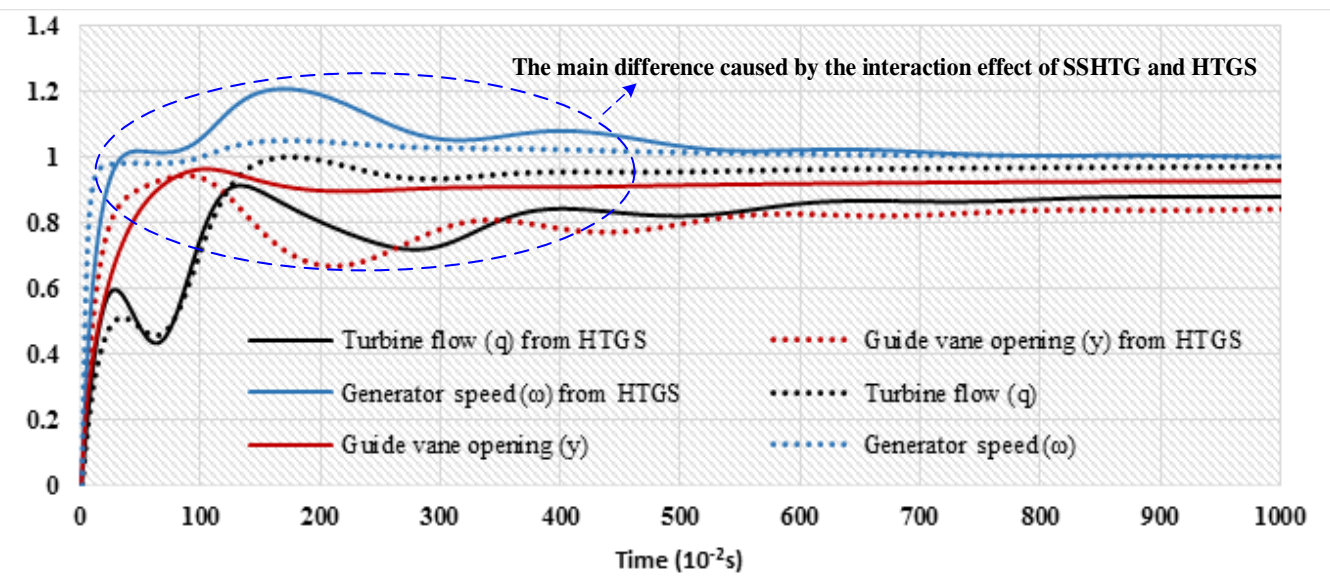

Fig. 11 Comparison of dynamic evolutions with respect to hydro-turbine flow, generator speed, and guide vane opening. The three dynamic parameters (q, $\omega$, and y) without words "from HTGS" come from simulation results of the model proposed in this study. The three dynamic parameters (q, $\omega$, and y) with words "from HTGS" come from simulation results of ref. 9. Symbol "二=)" refers to the modeling difference from this paper and ref. 37, which indicates that the interaction effect of HTGS and SSHTG changes the responses of $q, \omega$, and $y$ in this part.

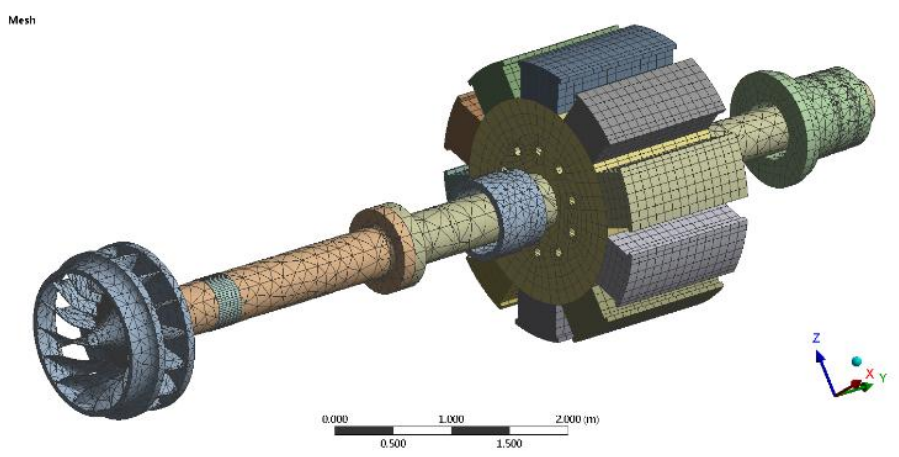

(a) Structural model of SSHTG

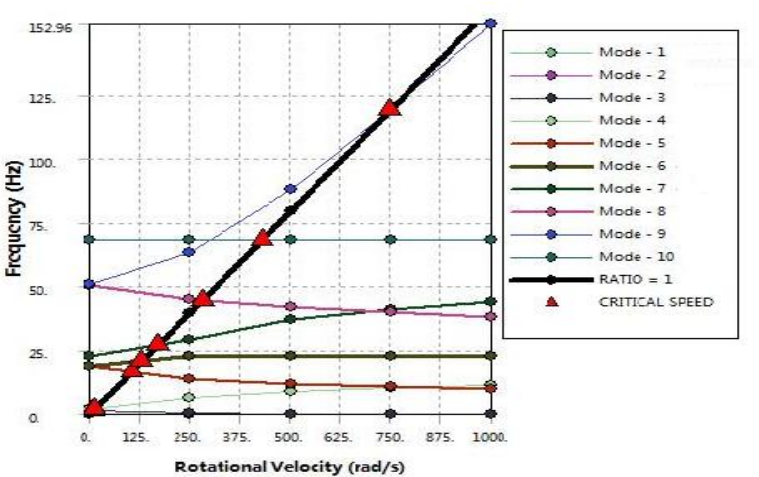

(b) Campbell diagram

Fig. 12 Modal analysis results calculated from ANSYS software. This model comes from ref. 37. The software of Pro/E is used to establish the 3D shafting model, and the element solid95 is adopted for its mesh generation. The grid includes 185699 units and 1023789 nodes.

Table 4 The comparison of the natural frequencies from the unified model and the model of ref. 3.

\begin{tabular}{ccc}
\hline Source & First-order mode (HZ) & Second order mode (HZ) \\
\hline The unified model & 16.85 & 20.45 \\
Ref. (37) & 16.62 & 20.72 \\
\hline
\end{tabular}

From Fig. 11, the main difference in the transient part is caused by the interaction of HTGS and 
SSHTG. The modeling results of the two models are similar to each other, except for the transient part labeled with symbol “=こ〉”. Hence, the proposed model in modeling HTGS's responses is verified. From Fig. 12 and Tab. 4, the natural frequencies calculated from the proposed model correspond closely to the frequencies of the FEW model, which verifies the correctness of the model proposed in modeling the SSHTG's responses. Therefore, the model proposed in this study is verified

From the above analysis, two challenges to bring the hydraulic turbine model into uncertainty theory framework are proposed. One challenge in modeling the HGS is the uncertainty in hydropower stations because of the run seconds or increased run years changing parameters. Monitoring systems can capture operation data of HGS, which may or may not be representative of uncertain parameters. The other challenge is the increasing model complexity. Both penstock systems and electrical systems have interactions. Establishing an integrated model would have the ability to access the impact of one system on the other, while the drawbacks are the simulated accuracy in stable operation and transient operations, as established in this study.

\section{Conclusions}

A rigorous study on parametric uncertainties in modeling HGS is presented. First, the hydro-turbine runner-a key component of the mathematical model is first proposed considering the inlet and outlet velocity vectors as well as the unbalanced hydraulic forces based on the Kutta-Zhoukowski condition. Second, uncertain outputs of conversion efficiency and unit vibration are investigated, and a normal distribution (i.e., average value $=0.786$, and the standard deviation is 0.106 ) for conversion efficiency is obtained. Third, the global sensitivity method is used to study the impact of parametric uncertainties on the conversion efficiency and unit vibration. The results verify that the most critical parameters for conversion efficiency are the relative height of the guide vane $(x x)$, the 
diameter ratio $(p p)$ and the gross water head $\left(h_{0}\right)$. The evaluation order of importance to unit vibration: the gross water head $\left(h_{0}\right)<$ the relative height of the guide vane $(x x)<$ the excretion coefficient $\left(s_{1}\right)<$ the angle $\left(b_{2}\right)<$ the excitation current $\left(i_{j}\right)<$ the diameter ratio $(p p)<$ the lift coefficient $\left(C_{y}\right)<$ the manufacturing angle error of the symmetrical blades $(b)$. Fourth, the new model is verified against two conventional models.

\section{Appendix}

The rub-impact forces: When the vibration amplitude of the rotor exceeds the gap between the generator stator and rotor, there will be collision, and we assume that it is elastic collision type. The effect of the friction heat is not considered in the collision process, and the stator radial stiffness is assumed to be a constant value. Then the rub-impact forces are written as [24]

$$
\left\{\begin{array}{l}
F_{n f}=\left(e-\delta_{0}\right) k_{r} \\
F_{t f}=f F_{n f}
\end{array}\right.
$$

where $e$ is the radial displacement, $e=\sqrt{x_{2}+y_{2}} ; \delta_{0}$ is the initial gap between the generator stator and rotor; $k_{r}$ is the radial stiffness of the stator; $f$ is the friction coefficient; $F_{n f}$ and $F_{t f}$ are radial and tangential components of the rub-impact forces, respectively. The radial component $F_{n f}$ can be further reduced to the rub-impact forces in $x$-direction and $y$-direction as:

$$
\left\{\begin{array}{l}
F_{x-r u b}=-H\left(e-\delta_{0}\right) \frac{\left(e-\delta_{0}\right) k_{r}}{e}\left(x_{2}-f y_{2}\right) \\
F_{y-r u b}=-H\left(e-\delta_{0}\right) \frac{\left(e-\delta_{0}\right) k_{r}}{e}\left(f x_{2}+y_{2}\right)
\end{array}\right.
$$

where $H(x)=\left\{\begin{array}{ll}0 & x<0 \\ 1 & x \geq 1\end{array}\right.$.

The film-oil forces: The film-oil forces adopt the same expressions used in ref. [23], and the expressions are

$$
\left\{\begin{array}{l}
F_{x}=F_{x 0}+k_{x x} x+k_{x y} y+d_{x x} D^{\alpha} x+d_{x y} D^{\alpha} y \\
F_{y}=F_{y 0}+k_{y x} x+k_{y y} y+d_{y x} D^{\alpha} x+d_{y y} D^{\alpha} y
\end{array},\right.
$$


where $F_{x 0}$ and $F_{y 0}$ are the oil-film forces at the quiescent operation point. Variables $k_{x x}, k_{x y}, k_{y x}, k_{y y}$, $d_{x x}, d_{y x}, d_{x y}$, and $d_{y y}$ in Eq. (3) are

$$
\left\{\begin{array}{l}
k_{x x}=\left(\frac{B}{d}\right)^{2} \frac{4 \varepsilon^{\prime}\left[2 \pi^{2}+\left(16-\pi^{2}\right) \varepsilon^{\prime 2}\right]}{\left(1-\varepsilon^{\prime 2}\right)^{2}\left[16 \varepsilon^{2}+\pi^{2}\left(1-\varepsilon^{\prime 2}\right)\right]} \\
k_{x y}=\left(\frac{B}{d}\right)^{2} \frac{\pi\left[-\pi^{2}+2 \pi^{2} \varepsilon^{\prime 2}+\left(16-\pi^{2}\right) \varepsilon^{\prime 4}\right]}{\left(1-\varepsilon^{\prime 2}\right)^{2.5}\left[16 \varepsilon^{\prime 2}+\pi^{2}\left(1-\varepsilon^{\prime 2}\right)\right]} \\
k_{y x}=\left(\frac{B}{d}\right)^{2} \frac{\pi\left[\pi^{2}+\left(\pi^{2}+32\right) \varepsilon^{\prime 2}+2\left(16-\pi^{2}\right) \varepsilon^{\prime 4}\right]}{\left(1-\varepsilon^{\prime 2}\right)^{2.5}\left[16 \varepsilon^{\prime 2}+\pi^{2}\left(1-\varepsilon^{\prime 2}\right)\right]} \\
k_{y y}=\left(\frac{B}{d}\right)^{2} \frac{4 \varepsilon^{\prime}\left[\pi^{2}+\left(\pi^{2}+32\right) \varepsilon^{\prime 2}+2\left(16-\pi^{2}\right) \varepsilon^{\prime 4}\right]}{\left(1-\varepsilon^{\prime 2}\right)^{3}\left[16 \varepsilon^{\prime 2}+\pi^{2}\left(1-\varepsilon^{\prime 2}\right)\right]} \\
d_{x x}=\left(\frac{B}{d}\right)^{2} \frac{2 \pi\left(\pi^{2}+2 \pi^{2} \varepsilon^{\prime 2}-16 \varepsilon^{\prime 2}\right)}{\left(1-\varepsilon^{\prime 2}\right)^{1.5}\left[16 \varepsilon^{\prime 2}+\pi^{2}\left(1-\varepsilon^{\prime 2}\right)\right]} \\
d_{x y}=\left(\frac{B}{d}\right)^{2} \frac{8 \varepsilon^{\prime}\left(\pi^{2}+2 \pi^{2} \varepsilon^{\prime 2}-16 \varepsilon^{\prime 2}\right)}{\left(1-\varepsilon^{\prime 2}\right)^{2}\left[16 \varepsilon^{\prime 2}+\pi^{2}\left(1-\varepsilon^{\prime 2}\right)\right]} \\
d_{y x}=d_{x y} \\
d_{y y}=\left(\frac{B}{d}\right)^{2} \frac{2 \pi\left(\pi^{2}+12 \pi^{2} \varepsilon^{\prime 2}-16 \varepsilon^{\prime 2}\right)}{\left(1-\varepsilon^{\prime 2}\right)^{2}\left[16 \varepsilon^{\prime 2}+\pi^{2}\left(1-\varepsilon^{\prime 2}\right)\right]}
\end{array}\right.
$$

where $B / d$ is the width-diameter ratio of the bearing; $\varepsilon^{\prime}$ is the eccentricity ratio, $\varepsilon^{\prime}=e_{1} / C ; e_{1}$ is the eccentricity of the bearing; $C$ is the radial gap of the bearing.

\section{The symmetric magnetic pull forces:}

We adopted the model of the symmetric magnetic pull forces as [23]:

$$
\left\{\begin{array}{l}
F_{x-\text {-й }}=\frac{r L \pi k_{j}^{2} I_{j}^{2}}{4 \mu_{0}}\left(2 \Lambda_{0} \Lambda_{1}+\Lambda_{1} \Lambda_{2}+\Lambda_{2} \Lambda_{3}\right) \cos \lambda \\
F_{y \text {-ий }}=\frac{r L \pi k_{j}^{2} I_{j}^{2}}{4 \mu_{0}}\left(2 \Lambda_{0} \Lambda_{1}+\Lambda_{1} \Lambda_{2}+\Lambda_{2} \Lambda_{3}\right) \sin \lambda
\end{array}\right.
$$

where $r$ is the generator rotor radius, $r=\sqrt{x_{1}^{2}+y_{1}^{2}} ; x_{1}$ and $y_{1}$ are coordinates of the generator rotor in $\mathrm{x}$-axis and $\mathrm{y}$-axis, respectively; $L$ is the length of the generator rotor. $\mu_{0}$ is the magnetic permeability of the air; $k_{j}$ is the coefficient of magneticmotive force for fundamental wave; $I_{j}$ is the exciting current of the generator; Moreover, there are four intermediate variables and no physical meaning, which are 


$$
\left\{\begin{array}{l}
\Lambda_{0}=\frac{\mu_{0}}{\delta_{0}} \frac{1}{\sqrt{1-\varepsilon^{2}}} \\
\Lambda_{1}=\frac{2 \mu_{0}}{\delta_{0}} \frac{1}{\sqrt{1-\varepsilon^{2}}}\left(\frac{1-\sqrt{1-\varepsilon^{2}}}{\varepsilon}\right) \\
\Lambda_{2}=\frac{2 \mu_{0}}{\delta_{0}} \frac{1}{\sqrt{1-\varepsilon^{2}}}\left(\frac{1-\sqrt{1-\varepsilon^{2}}}{\varepsilon}\right)^{2} \\
\Lambda_{3}=\frac{2 \mu_{0}}{\delta_{0}} \frac{1}{\sqrt{1-\varepsilon^{2}}}\left(\frac{1-\sqrt{1-\varepsilon^{2}}}{\varepsilon}\right)^{3}
\end{array} .\right.
$$

where $\delta_{0}$ is the initial gap between the generator stator and rotor; $\varepsilon$ is eccentricity ratio, $\varepsilon=r / \delta_{0}$.

\section{Acknowledgements}

This work was supported by the Scientific Research Foundation of the National Natural Science

Foundation Outstanding Youth Foundation (51622906), National Science Foundation (51479173), Fundamental Research Funds for the Central Universities (201304030577), scientific research funds of Northwest A\&F University (2013BSJJ095), the Scientific Research Foundation on Water Engineering of Shaanxi Province (2013slkj-12), the Science Fund for Excellent Young Scholars from Northwest A\&F University, and the Shaanxi Nova program (2016KJXX-55).

\section{References}

[1] Li XZ, Chen ZJ, Fan XC, Cheng ZJ. Hydropower development situation and prospects in China. Renewable \& Sustainable Energy Reviews, 2018;82(1):232-239.

[2] Yang ZC. Global Hydropower capacity to "double" by 2050. http://economy.southcn.com/e/2015-05/20/content_124617746.htm.

[3] Su WT, Li XB, Lan CF, et al. Chaotic dynamic characteristics of pressure fluctuation signals in hydro-turbine. Journal of Mechanical Science and Technology, 2016, 30(11): 5009-5017.

[4] Zhang CB, Yang MJ, Li JY. Detailed modelling and parameters optimisation analysis on governing system of hydro-turbine generator unit. IET Generation Transmission \& Distribution, 2018, 12(5): 1045-1051.

[5] Sarasúa JI, Pérez-Díaz JI, Wilhelmi JR, Sánchez-Fernández JÁ. Dynamic response and governor tuning of a long penstock pumped-storage hydropower plant equipped with a pump-turbine and a doubly fed induction generator. Energy Conversion \& Management. 2015;106:151-164.

[6] Li H, Chen D, Zhang H, Wang FF, Ba DD. Nonlinear modeling and dynamic analysis of a hydro-turbine governing system in the process of sudden load increase transient. Mechnical Systems and Signal Processing, 2016, 80: 414-428.

[7] Riasi A, Tazraei P. Numerical analysis of the hydraulic transient response in the presence of surge tanks and relief valves. Renewable Energy, 2017;107: 138-146.

[8] Rezghi A., Riasi A. Sensitivity analysis of transient flow of two parallel pump-turbines operating at runaway. Renewable Energy, 2016;86: 611-622.

[9] IEEE Group. Hydraulic-turbine and turbine control-models for system dynamic studies. IEEE Transactions on Power 
Systems, 1992, 7(1): 167-179.

[10] Guo W, Yang J. Modeling and dynamic response control for primary frequency regulation of hydro-turbine governing system with surge tank. Renewable Energy, 2018, 121: 173-187.

[11] Guo W, Yang J, Teng Y. Surge wave characteristics for hydropower station with upstream series double surge tanks in load rejection transient. Renewable Energy, 2017, 108: 488-501.

[12] Xu B, Chen D, Zhang H, Wang F. Modeling and stability analysis of a fractional-order Francis hydro-turbine governing system. Chaos Solitons \& Fractals, 2015;75:50-61.

[13] Zhang H, Chen D, Xu B, Wang F. Nonlinear modeling and dynamic analysis of hydro-turbine governing system in the process of load rejection transient. Energy Conversion \& Management. 2015;90:128-137.

[14] Yu X, Zhang J, Fan C, Chen S. Stability analysis of governor-turbine-hydraulic system by state space method and graph theory. Energy. 2016;114:613-622.

[15] Hajagos LM, Basler MJ. IEEE Standard 421.5-IEEE Recommended Practice for Excitation System Models for Power System Stability Studies. Power Engineering Society General Meeting, 2005. pp. 334-336.

[16] Shen ZY. Hydro-turbine governing system. China Water \& Power Press, 2008, pp. 186.

[17] Xu B, Chen D, Tolo S, Patelli E, Jiang Y. Model validation and stochastic stability of a hydro-turbine governing system under hydraulic excitations. International Journal of Electrical Power \& Energy Systems. 2018;95:156-165.

[18] Liang J, Yuan X, Yuan Y, Chen Z, Li Y. Nonlinear dynamic analysis and robust controller design for Francis hydraulic turbine regulating system with a straight-tube surge tank. Mechanical Systems \& Signal Processing. 2017;85:927-946.

[19] Zeng Y, Zhang L, Guo Y, Qian J, Zhang C. The generalized Hamiltonian model for the shafting transient analysis of the hydro turbine generating sets. Nonlinear Dynamics. 2014;76:1921-33.

[20] Yang WJ, Norrlund P, Saarinen L, et al. Wear and tear on hydro power turbines - Influence from primary frequency control. Renewable Energy, 2016, 87: 88-95.

[21] Xu B, Wang F, Chen D, Zhang H. Hamiltonian modeling of multi-hydro-turbine governing systems with sharing common penstock and dynamic analyses under shock load. Energy Conversion \& Management. 2016;108:478-487.

[22] Jiang N, Chiang HD. A Two-Time Scale Dynamic Correction Method for Fifth-Order Generator Model Undergoing Large Disturbances. IEEE Transactions on Power Systems. 2016;31:3616-23.

[23] Xu BB, Chen DY, Zhang H, Zhou R. Dynamic analysis and modeling of a novel fractional-order hydro-turbine-generator unit. Nonlinear Dynamics, 2015; 81: 1263-1274.

[24] Zhang LK. Nonlinear dynamic analysis of shaft system for hydroelectric generating set. Dalian University of Technology, 2014, pp. 23.

[25] Tong WM. Analysis of spindle swing caused by hydraulic unbalance of hydraulic turbine runner. Sichuan Water Power, 1986, 1: 42-46. (In Chinese)

[26] Jiang J. Fluid dynamic analysis and optimization method for vertical-axis turbine: Improvement and Application. Harbin Engineering University, 2012.

[27] He BH. Working principle of hydraulic turbine. https://wenku.baidu.com/view/b8dd40d0ad51f01dc281f1c0.html, pp. 15.

[28] Xu Y, Peng Y, Zheng X, Dearn KD, Xu H, Hu X. Synthesis and tribological studies of nanoparticle additives for pyrolysis bio-oil formulated as a diesel fuel. Energy. 2015;83:80-88.

[29] Xu B, Yan DL, Chen DY, et al. Sensitivity analysis of a Pelton hydropower station based on a novel approach of turbine torque. Energy Conversion and Management, 2017, 148: 785-800.

[30] Perers R, Lundin U, Leijon M. Saturation Effects on Unbalanced Magnetic Pull in a Hydroelectric Generator With an Eccentric Rotor. IEEE Transactions on Magnetics. 2007;43:3884-90.

[31] Zheng Y, Chen DX. Hydro-turbine. China Water \& Power Press, 2011, pp. 47. (In Chinese)

[32] Xu BB, Chen DY, Gao X, Tomas C, Patelli E. Dynamic evolution of a hydraulic-mechanical-electric system with randomly fluctuating speed. Nonlinear Dynamics, 2018, 92(4): 1801-1813. 
[33] Sobol IM. Sensitivity estimates for nonlinear mathematical models. Math. Model. Comput. Exp., 1993, 2(1): $112-118$.

[34] Luo XQ, Ji JT, Lu P, Hua Y. Steady flow analysis of Francis Trubine. Journal of Mechanical Engineering. 2009;45:208-13.

[35] Patelli E, Pradlwarter HJ, Schuëller GI. Global sensitivity of structural variability by random sampling. Computer Physics Communications. 2010;181:2072-81.

[36] Angelis MD, Patelli E, Beer M. Advanced Line Sampling for efficient robust reliability analysis. Structural Safety. 2015;52:170-82.

[37] Wang WC. Study on Vibration characteristics of hydro-turbine generator units. The 21st China Symposium on Hydropower equipment, 2017. 